\title{
Champignons hallucinogènes d'Europe et des Amériques : mise au point mycologique et toxicologique
}

\section{Mycology and toxicology of hallucinogenic mushrooms in Europe and Americas}

Régis COURTECUISSE ${ }^{(1) *}$, Marc DEVEAUX ${ }^{(2)}$,

(1) Département de Botanique, Faculté des Sciences Pharmaceutiques et Biologiques, Université de Lille 2, rue du Professeur Laguesse - BP 83 - F-59006 LILLE CEDEX - FRANCE (2) Institut de Médecine Légale, Faculté de Médecine, Université de Lille 2, rue André Verhaeghe F-59045 LILLE CEDEX - FRANCE

* Auteur à qui adresser la correspondance : Régis COURTECUISSE, Département de Botanique, Faculté des Sciences Pharmaceutiques et Biologiques, Université de Lille 2, rue du Professeur Laguesse - BP 83 F-59006 LILLE CEDEX - FRANCE - Tél : 0320964713 - E-mail : rcourtec@pharma.univ-lille2.fr

(Reçu le 19 janvier 2004 ; accepté le 6 février 2004)

\section{$R \mathbf{E} S \boldsymbol{U} M E$}

L'usage récréatif des champignons hallucinogènes est maintenant bien établi, en Europe et en Amérique du Nord. En Amérique Centrale, ils sont également utilisés dans un but spirituel et religieux. Les principes actifs à noyau indolique sont la psilocine et la psilocybine. Le syndrome hallucinogène causé par quelques milligrammes de psilocybine est très classique, avec dépersonnalisation, euphorie et dysphorie. Le traitement est symptomatique. La liste des espèces concernées et leur répartition sur les deux continents sont constamment révisées de manière critique par les mycologues, et nous en présentons l'état actuel. Le genre Psilocybe est le plus important, suivi par le genre Panaeolus. Le nombre d'espèces potentiellement hallucinogènes avoisine 150 et nous en présentons une liste extensive s'appuyant sur 280 références bibliographiques.

Les cas prouvés d'intoxication chez l'homme restent cependant très rares et le diagnostic est essentiellement clinique. La mise en évidence et le dosage de la psilocine dans le sang et l'urine sont maintenant parfaitement réalisables par des méthodes de chromatographie liquide et de chromatographie gazeuse couplée à un détecteur de masse. Les quelques cas

\section{SUMMARY}

The recreational use of Fungi is now well established, in Europe and in North America as well. In Central America, they are also in use but mainly for spiritual and religious purpose. The indolic active molecules are psilocin and psilocybin. The hallucinogenic syndrome, induced by a few milligrams of psilocybin is very well known, with loss of personality, euphoria and dysphoria. The treatment is symptomatic. The list of involved species and their distribution on both continents are constantly critically revised by mycologists and we present their current state. The genus Psilocybe is predominant, followed by the genus Panaeolus. The number of hallucinogenic species may be around 150 and we present here an extended list, based on 280 scientific references. Nevertheless the number of attested cases of human poisoning remain very low and the diagnostic is mainly clinical. Testing and dosing psilocybin in blood and urine may now be achieved using liquid chromatography methods or gas chromatography-mass spectrometry. For psilocybin the few cases reported in scientific literature show limits of quantification about $5 \mathrm{ng} / \mathrm{mL}$ in urine. Detection in urine must be processed during the 2 or 3 days after ingestion of the fungi and 
décrits dans la littérature indiquent, pour la psilocine, des limites de quantification de l'ordre de $5 \mathrm{ng} / \mathrm{mL}$ dans l'urine. La détection dans l'urine peut se faire pendant les 2 ou 3 jours suivants une ingestion de champignons, et les prélèvements biologiques doivent être absolument protégés de l'oxydation.

\section{MOTS-CLÉS}

Psilocybine, psilocine, champignons hallucinogènes.

\section{Introduction}

A l'époque précortézienne, les Aztèques, les Mixtèques, les Nahuas, les Mayas, les Chinantèques, les Chatinos, les Mije, les Zapotèques et surtout les Mazatèques utilisaient déjà les champignons hallucinogènes, qui avaient une place très importante dans leurs rituels religieux et divinatoires (1-4). On pense cependant que leur utilisation ne se limitait pas à ces populations d'Amérique Centrale, mais était également courante dans une grande partie de l'Amérique du Sud (3). Rapidement interdite par les autorités ecclésiastiques espagnoles, les cérémonies rituelles ont cependant perduré tout en restant quasiment secrètes pendant plus de 200 ans. L'usage en a été redécouvert par R.G. Wasson et sa femme V.P. Wasson au début des années 1950 (5). Ils entraînèrent R. Heim, R. Cailleux et A. Hofmann dans leur aventure : fonder puis développer l'éthnomycologie $(3,6)$. L'usage des champignons hallucinogènes s'est alors développé en Amérique du Nord pendant plusieurs dizaines d'années, sous l'influence des écrivains de la beat generation. Depuis, il a connu un intérêt croissant en Europe et en France, allant de la recherche frénétique des stations où poussent ces champignons jusqu'à la vente par correspondance et l'achat sur l'Internet (4). Le nombre d'affaires judiciaires, après avoir augmenté rapidement en France, est maintenant pratiquement stable. On remarquera que l'usage des champignons hallucinogènes n'est pas mentionné dans les rapports de l'observatoire européen des drogues et des toxicomanies (O.E.D.T.) (7), mais que l'utilisation des hallucinogènes (en fait essentiellement le LSD) n'est pas négligeable et qu'elle entre très vraisemblablement dans le cadre d'une polytoxicomanie. L'enquête ESCAPAD 2000 notait qu'en France, vers l'âge de 17 ans, environ $5 \%$ des garçons interrogés avaient déjà consommé au moins une fois des champignons hallucinogènes (8). Ceci a été aussi vérifié localement dans le sud de la France (9). biological samples must be strictly protected from oxidation.

\section{KEY-WORDS}

Psilocybin, psilocin, hallucinogenic mushrooms, magic mushrooms.

\section{Effets de la psilocybine}

Les effets hallucinogènes des champignons mexicains (teonanactl) ont été décrits par des moines espagnols Bernardino de Sahagun et Torribio de Benavente dès $1569(2,10)$, avec une tendance certaine à noircir le tableau car aucune hallucination agréable n'était rapportée. La première observation d'un syndrome hallucinatoire publiée dans une revue médicale scientifique date de 1799, mais il s'agissait d'une ingestion accidentelle (11).

Ils ont été décrits ensuite avec force détails au $\mathrm{XX}^{\mathrm{m} m \mathrm{c}}$ siècle par ceux qui en ont bénéficié (12-14). Les effets des champignons hallucinogènes ne sont pas très différents de ceux produits par le LSD, mais on ne dispose que de très peu d'observations bien documentées (15). Cependant, l'action de la psilocybine pure a été décrite de façon très précise par Shulgin (14) lors d'expériences sur lui-même, où il constatait que l'ampleur des phénomènes hallucinatoires était dose-dépendante. Les effets cliniques sont de trois ordres, somatiques, sensoriels et émotionnels et peuvent être résumés ainsi: la symptomatologie se développe dans les 20 à 30 minutes qui suivent la prise orale, dure en général moins de 4 heures et disparaît complètement dans les 12 heures $(4,8,15-19)$.

Les effets somatiques apparaissent les premiers : augmentation de la fréquence cardiaque, modifications (en hausse ou en baisse) de la pression artérielle, mydriase, érection pileuse, légère élévation thermique, congestion faciale. On observe aussi des nausées et une sécheresse de la bouche. L'asthénie et la somnolence sont présentes dans la plupart des cas et peuvent persister 24 heures et plus. D'une façon générale, la diurèse est augmentée. Il n'a pas été mis en évidence d'effets biologiques caractéristiques, à part une élévation des transaminases $(19,20)$. La consommation répétée de champignons hallucinogènes peut avoir des conséquences plus graves : un cas documenté d'infarctus du myocarde grave a été décrit en Pologne (20), ainsi que plusieurs cas d'insuffisance rénale et d'effets neurotoxiques $(21,22)$.

Les effets sensoriels et émotionnels dépendent de différents facteurs : dose ingérée, état psychologique du 
sujet, préparation aux effets. Ils peuvent être différents d'une prise à l'autre. Les réflexes ostéotendineux sont le plus souvent exagérés. L'équilibre et la coordination motrice sont perturbés. Les troubles de la sensibilité objective se traduisent essentiellement par des troubles hyperesthésiques.

Les modifications de l'humeur sont autant euphoriques que dysphoriques, les phase dépressives alternant avec les phases d'euphorie. La descente se vit parfois douloureusement.

Les hallucinations rapportées sont habituellement visuelles et très élaborées (phosphènes, kaléidoscopes, mosaïques), parfois auditives (acouphènes), tactiles ou somesthésiques $(3,8)$. La perception des couleurs, du temps et de l'espace est perturbée. Des phénomènes de synesthésie, où des couleurs semblent avoir une odeur, sont souvent rapportés. Enfin, des sensations de transformation corporelle sont fréquemment signalées. Lorsqu' apparaissent ces phénomènes, le sujet n'est pas en mesure la plupart du temps d'en percevoir la nature, et ce n'est qu'après coup qu'il est capable de critiquer son trouble et de le définir. Le traitement est purement symptomatique et comprend l'administration de tranquillisants (23). Si une tolérance peut se développer en quelques jours, pour disparaître aussi rapidement, aucune dépendance physique n'a encore été mise en évidence $(8,16)$. Les complications psychiatriques peuvent être graves et elles ont été bien étudiées par Abraham et Halpern (24-26).

Les symptômes psychiatriques observés lors de l'utilisation de substances hallucinogènes sont décrits de manière précise dans un chapitre de la Classification Internationale des Maladies (CIM-1O), intitulé "Troubles mentaux et du comportement liés à l'utilisation de substances psychoactives" (F10-F19), dont les subdivisions F16.0, F16.1 et F16.5 peuvent s'appliquer à l'usage de champignons hallucinogènes (27).

Les hallucinations surviennent après l'ingestion de 5 à $15 \mathrm{~g}$ de champignons (soit 10 à 20 sporophores secs), ce qui correspond à environ 4 à $25 \mathrm{mg}$ de psilocybine (4, 21, 24-26, 28, 29). Gérault et coll. (30) ont proposé une échelle de toxicité selon la dose ingérée (Tableau I). Il suffit de $1 \mathrm{mg}$ de psilocybine par voie intraveineuse pour obtenir les mêmes effets (28). Les intoxications mortelles directement dues à l'ingestion de champignons hallucinogènes sont extrêmement rares : dans sa dernière revue de la littérature, en 2002, Karch (1) estime que moins de 5 cas ont été publiés depuis un demisiècle. En 2004, Moffat et coll. (31) ne signalent aucun décès non plus. Les décès indirects (traumatismes mortels pendant les hallucinations) existent, mais n'ont été documentés que si la notion de consommation de champignons était connue, ce qui est très rare (32).
Tableau I : Échelle de toxicité des champignons hallucinogènes proposée par Gérault et coll. (30).

\begin{tabular}{|c|c|c|}
\hline $\begin{array}{c}\text { N de sporophores } \\
\text { (masse) }\end{array}$ & $\begin{array}{c}\text { Dose estimée de } \\
\text { psilocybine }\end{array}$ & Effets attendus \\
\hline $5(\mathrm{~g})$ & $5-10 \mathrm{mg}$ & dose minimale efficace \\
\hline $10(2 \mathrm{~g})$ & $10-20 \mathrm{mg}$ & "voyage" moyen à bon \\
\hline $20-40(4-8 \mathrm{~g})$ & $20-80 \mathrm{mg}$ & très bon "voyage" \\
\hline $60(12 \mathrm{~g})$ & $60-120 \mathrm{mg}$ & mauvais "voyage" \\
\hline
\end{tabular}

\section{Métabolisme de la psilocy- bine}

\section{Principes actifs hallucinogènes et biosyn- thèse dans les champignons}

Environ une centaine de plantes et champignons hallucinogènes ont été répertoriés $(33,34)$, mais curieusement les principes actifs n'appartiennent qu'à quelques familles chimiques. A part les cannabinoïdes ce sont des alcaloïdes, avec l'un des groupements suivants : phenylpropène, dibenzopyrane, isoxazole, tropane, quinolizidine, phényléthylamine, isoquinoline, tryptamine, ergoline, (-carboline et ibogaindole $(24,35)$. Les principes actifs des champignons hallucinogènes sont des dérivés indoliques : la psilocybine (4-phosphoryloxy- $N, N$-diméthyltryptamine), qui est le plus important, et la psilocine (4-hydroxy- $N, N$-diméthyltryptamine). Hofmann les a isolé et identifié dans le Psilocybe semilanceata, puis les a synthétisé $(36,37)$. Leurs structures sont représentées Figure 1. La biosynthèse dans le mycélium pourrait être la suivante $(4,38)$ : la tryptamine est d'abord méthylée, puis phosphorylée en baeocystine. Une seconde méthylation conduit à la psilocybine. A l'inverse, une déméthylation produit la norbaecystine. La psilocine est produite par déphosphorylation (biosynthèse schématisée Figure 2).

\section{Métabolisme de la psilocybine chez l'homme}

La psilocybine est très rapidement déphosphorylée en psilocine par des enzymes de la muqueuse intestinale, phosphatase alcaline et estérases non spécifiques (4, 28): c'est la psilocine qui est le véritable agent pharmacologiquement actif. Elle est ensuite transformée en 4-hydroxyindole-acétaldéhyde (4-HIA) puis en acide 4-hydroxyindole-3-acétique (4-HIAA) et en 4hydroxytryptophol (28). Le dérivé glycuroconjugué de la psilocine prédomine dans l'urine mais n'est pas toujours mis en évidence $(28,39,40)$. Ce métabolisme est représenté sur la Figure 2. Hasler et coll. (21) ont comparé les paramètres pharmacocinétiques dans le plasma pour une administration de psilocybine par voie orale et pour une administration intraveineuse, avec des doses 


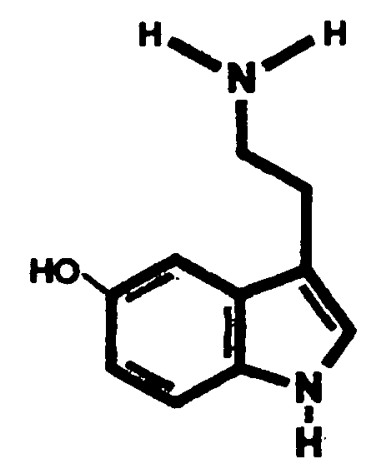

Sérotonine

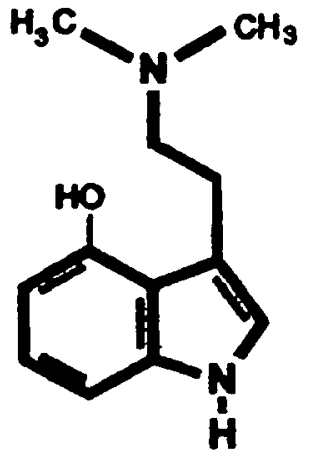

Psilocine

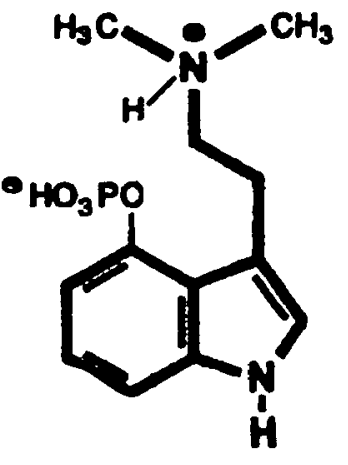

Psilocybine

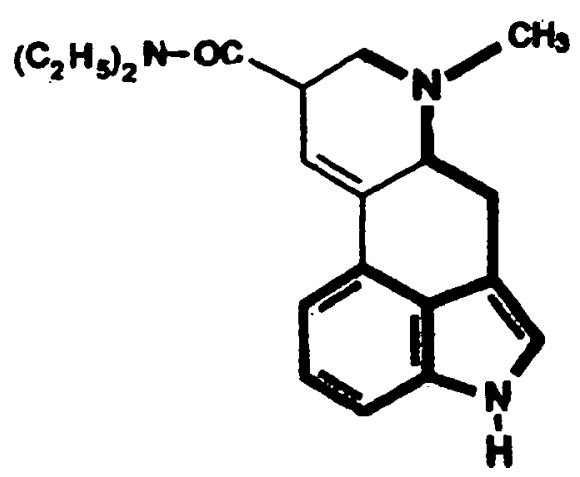

LSD-25

Figure 1 : Formules planes développées de la psilocybine et de la psilocine; comparaison avec la sérotonine et le LSD-25.

CHAMPIGNON

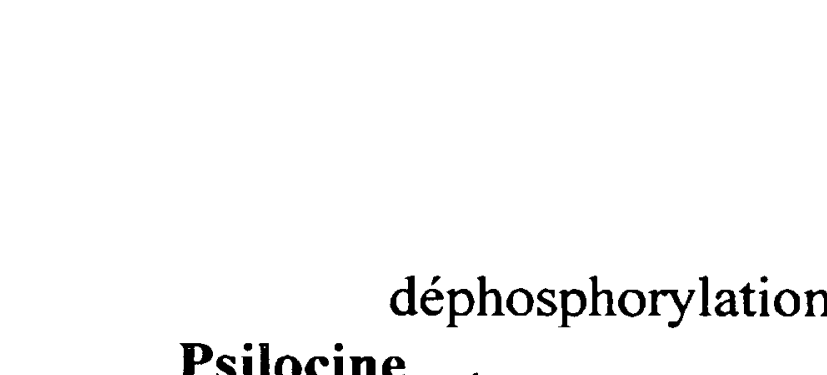

Psilocine

\section{Tryptamine}

méthylation

phosphorylation

Baeocystine

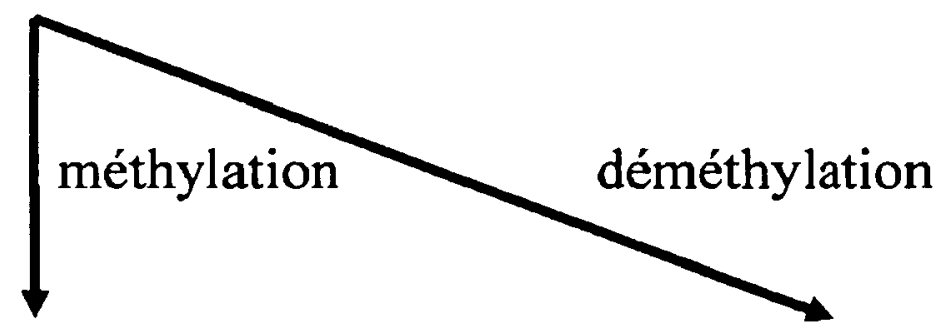

Psilocybine

Norbaeocystine

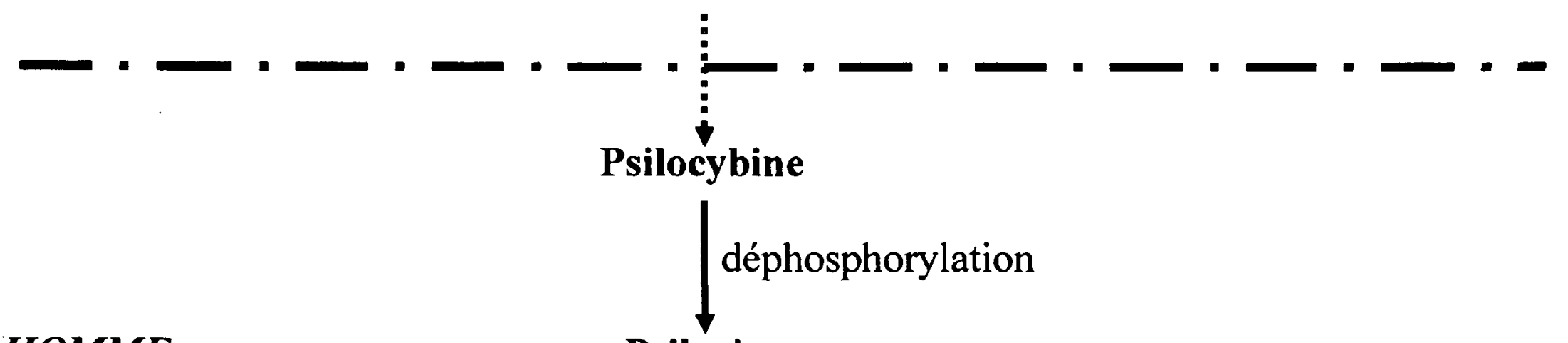

HOMME

Psilocine

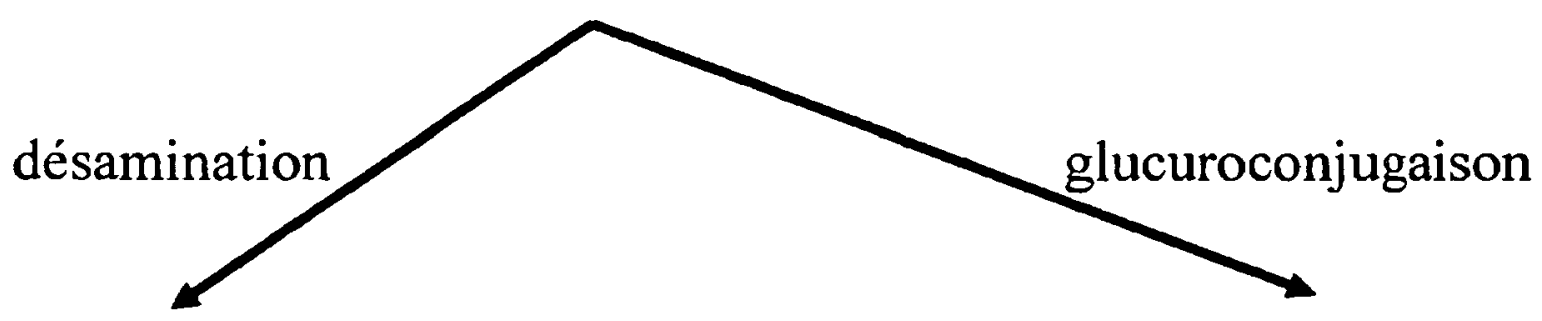

4-hydroxyindol-3-yl-acétaldéhyde

Psilocine-O-glucuronide

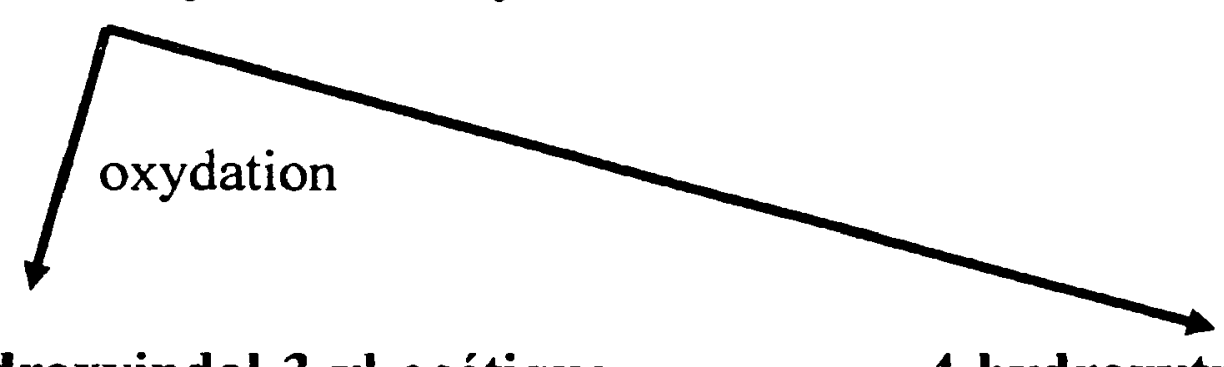

acide 4-hydroxyindol-3-yl-acétique

4-hydroxytryptophol

Figure 2 : Biosynthèse de la psilocybine dans le mycélium et métabolisme chez l'homme. 
de psilocybine de $15 \pm 3 \mathrm{mg}$, soit $0,224 \pm 0,020 \mathrm{mg} / \mathrm{kg}$. Lindenblatt et coll. (41) ont établi ces paramètres pour la psilocine uniquement, avec des doses de $15 \mathrm{mg}$ par voie orale. Le tableau II reprend leurs résultats, mais limités à l'étude par voie orale qui est de loin la voie d'administration la plus fréquente chez les usagers (42). Hasler et coll. (28) estiment qu'environ la moitié de la dose ingérée $(52 \pm 20 \%)$ est transformée en psilocine à partir de la prodrogue qu'est la psilocybine. Pour eux, la clairance plasmatique de la psilocine est de $3,1 \pm 0,7 \mathrm{~L} / \mathrm{min}$, son volume de distribution de $277 \pm$ $92 \mathrm{~L}$ et son temps moyen de transit de 90,9 $\pm 28,2 \mathrm{~min}$. On peut retrouver la psilocine dans les urines pendant les 36 à 48 heures qui suivent la consommation (29, 43).

Tableau II : Paramètres pharmacocinétiques de la psilocine et de son métabolite le 4-HIAA après administration de psilocybine par voie orale. Moyennes et écarts-type (entre parenthèses). D'après Hasler (28) et Lindenblatt (41).

\begin{tabular}{|c|c|c|c|c|}
\hline & & $\begin{array}{c}C_{\max } \\
(\mathrm{ng} / \mathrm{ml})\end{array}$ & $\begin{array}{l}t_{\max } \\
(\min .)\end{array}$ & $\begin{array}{l}t_{12 \beta} \\
(\mathrm{min})\end{array}$ \\
\hline $\begin{array}{l}\text { Hasler et coll. } \\
\text { psilocine } \\
\text { 4-HIAA }\end{array}$ & 6 sujets & $\begin{array}{l}8,2(2,8) \\
150(61)\end{array}$ & $\begin{array}{l}105(37) \\
113(41)\end{array}$ & $\begin{array}{l}163,3(63,5) \\
144,5(96,7)\end{array}$ \\
\hline $\begin{array}{l}\text { Lindenblatt et coll. } \\
\text { psilocine }\end{array}$ & 7 sujets & $11,3(5,5)$ & $81(9)$ & 135,0 \\
\hline
\end{tabular}

\section{Législation en France}

L'arrêté du 22 février 1990 (publié au Journal Officiel du 7 juillet 1990) fixe la liste des substances classées comme stupéfiants. La psilocine et la psilocybine, leurs isomères, leurs sels et les préparations en contenant sont cités dans l'annexe III. Les champignons hallucinogènes, "notamment des genres stropharia, conocybe et psilocybe" sont inscrits à l'annexe IV. Nous avions déjà fait remarquer en 1998 (4) que le Journal Officiel, pourtant si pointilleux sur l'orthographe, ne respectait pas la nomenclature en omettant d'écrire les noms de genre avec une majuscule et en italique, et que les espèces concernées du genre Conocybe appartiennent en fait aux Pholiotina (ancien sous-genre, aujourd'hui considéré comme un genre autonome). On doit constater que rien n'a changé ! Cependant, l'arrêté reste assez imprécis pour ne pas exclure de la législation sur les stupéfiants d'autres champignons ayant des propriétés hallucinogènes. Dans les autres pays d'Europe, la législation est variable : les champignons eux-mêmes ne sont pas toujours classés comme stupéfiants, alors que la psilocybine et la psilocine le sont, car inscrites à un des tableaux de la convention internationale de 1961 sur les stupéfiants. Ce classement peut être consulté sur le site de l'AFSSaPS : (http://afssaps.sante.fr/htm/10/pharma/classem).

L'identification des champignons, la recherche et le dosage de psilocybine et de psilocine seront donc primordiaux en cas de saisies de champignons.

Psilocybine et psilocine peuvent être assez facilement synthétisées $(44,45)$, ce qui permettrait, outre la fabrication et l'usage illicite, la mise au point de réactifs d'immunoanalyse (46).

\section{Dosage des principes actifs dans les champignons}

Les sporophores doivent être le plus possible conservés à l'abri de la lumière et séchés à $40^{\circ} \mathrm{C}$. Des réactions aux réactifs de Melzer (pas de changement ou un faible jaunissement) et aux réactifs d'Ehrlich et de Keller (couleur violacée) sont caractéristiques du genre Psilocybe, mais ne suffisent pas (42). Stipes et chapeaux peuvent être broyés au mortier séparément, car on sait que les teneurs en principes actifs ne sont pas identiques dans les différentes parties des champignons $(47,48)$. Avant l'analyse, le broyat doit être déshydraté jusqu'à poids constant. L'extraction se fait par le méthanol, soit par agitation une nuit $(10 \mathrm{~mL} / \mathrm{g}$ de broyat) (49), soit par ultrasonication $120 \mathrm{~min}$ à $50^{\circ} \mathrm{C}$ maximum (42). La masse d'extrait sec nécessaire est inférieure à un gramme, mais il est tout à fait possible de travailler à partir de $100 \mathrm{mg}$ environ (42). Les résultats doivent toujours être exprimés en référence à la masse sèche.

De nombreuses méthodes en CLHP ont été écrites, que ce soit avec un détecteur UV, un détecteur fluorimétrique ou maintenant avec un détecteur électrochimique (revues dans les réf. 4, 23, 42, 50). En CG-SM, la dérivation est indispensable car la psilocybine est déphosphorylée à la chaleur; elle peut se faire par le BSTFA à $140^{\circ} \mathrm{C}$, ou le BSTFA-TMCS à $100^{\circ} \mathrm{C}$ ou mieux par le MSTFA à $70^{\circ} \mathrm{C}(4,49,50)$.

L'utilisation de l'électrophorèse capillaire de zone permet d'atteindre des limites de détection satisfaisantes : $45 \mu \mathrm{g} / \mathrm{g}$ de champignon $(51,52)$. La chromatographie électrocinétique micellaire est moins sensible : 300 $\mu \mathrm{g} / \mathrm{g}$ (53), mais suffisante pour identifier et doser les principes actifs dans les champignons. L'identification de la psilocybine et surtout de la psilocine par spectrométrie à mobilité d'ions (Ionscan) n'en est qu'à ses débuts et semble très prometteuse : la limite de détection est de l'ordre de $1 \mathrm{ng}$ de psilocine $(50,53)$.

Pour chaque espèce reconnue comme hallucinogène, les teneurs en principes actifs des champignons sont données dans l'Annexe 1, à la rubrique «Dos.». 


\section{Dosages de la psilocine dans les milieux biologiques}

Dans le plasma, on ne retrouve classiquement que la psilocine, libre et conjuguée, et parfois le 4-HIAA (29). Dans l'urine, on peut mettre aussi en évidence les métabolites suivants : 4-HIA, 4-HIAA et 4-hydroxytryptophol $(28,29,43)$. Le sang doit être recueilli sans anticoagulant et le plasma séparé très rapidement. Dés le prélèvement effectué, il faut éviter l'oxydation par addition de $5 \%$ (v:v) d'acide ascorbique à $94 \mathrm{~g} / \mathrm{mL}$, congélation immédiate à $-80^{\circ} \mathrm{C}$ et lyophilisation $(28$, $29,41,43)$. L'hydrolyse des dérivés conjugués se fait à pH 5 par la -glucuronidase pendant $5 \mathrm{~h}$ à $40^{\circ} \mathrm{C}(28,29$, 39). Les méthodes utilisées sont la CLHP avec un détecteur électrochimique, sur une colonne Spherisorb RP-8 par exemple $(29,41,54)$, mais un système REMEDi HS a déjà été utilisé avec succès pour doser la psilocine dans l'urine (39). La CG-SM après dérivation est très performante, avec le proadifen ou la morphine deutérée comme étalon interne $(39,40,49,50)$. (Voir tableau III). Les limites de quantification pour la psilocine sont de $10 \mathrm{ng} / \mathrm{mL}$ dans l'urine et de 0,8 $\mathrm{ng} / \mathrm{mL}$ dans le plasma (28). Hasler et coll. (29) estiment avec raison que les analyses devraient se faire en CLHP-SM/SM, pour pallier les problèmes de thermolabilité et de très faibles concentrations des principes actifs dans le sang.

Tableau III : Concentrations sanguines et urinaires de psilocybine et de psilocine retrouvées dans la littérature (exprimées en $\mathrm{ng} / \mathrm{mL}$ ). T est le délai écoulé entre l'ingestion et le prélèvement. $Q$ est la quantité de psilocybine ingérée (en $m g$ ). ND : données non disponibles.

\begin{tabular}{|l|c|c|c|c|c|}
\hline & $\mathrm{T}$ & $\mathrm{Q}$ & sérum & urine & ref. \\
\hline psilocine libre & $5-6 \mathrm{~h}$. & $20-30 \mathrm{mg}$ & 18 & 230 & $(39)$ \\
psilocine totale & $5-6 \mathrm{~h}$. & $20-30 \mathrm{mg}$ & 52 & 1760 & $(39)$ \\
psilocine libre & $2-3 \mathrm{~h}$. & $90 \mathrm{mg}$ & 7 & 2300 & $(32)$ \\
psilocine totale & $2-3 \mathrm{~h}$. & $90 \mathrm{mg}$ & 91 & 5400 & $(32)$ \\
psilocine libre & $2-3 \mathrm{~h}$. & $90 \mathrm{mg}$ & 6 & 30 & $(32)$ \\
psilocine totale & $2-3 \mathrm{~h}$. & $90 \mathrm{mg}$ & 170 & 1950 & $(32)$ \\
psilocine libre & $1-2 \mathrm{~h}$. & $15 \mathrm{mg}$ & 8,2 & ND & $(28)$ \\
psilocine libre & $1-2 \mathrm{~h}$. & $11 \mathrm{mg}$ & ND & 17 & $(29)$ \\
psilocine libre & $2-4 \mathrm{~h}$. & $13 \mathrm{mg}$ & ND & 871 & $(29)$ \\
\hline
\end{tabular}

\section{Liste commentée des cham- pignons hallucinogènes d'Europe et des Amériques}

Il n'existe pas de liste clairement délimitée et non ambiguë des champignons en cause dans le syndrome hallucinogène. C'est une situation frustrante dans bien des circonstances et difficile à comprendre pour les non mycologues. La mycologie est une science dont l'objet se montre particulièrement capricieux et récalcitrant et nous expliquerons les multiples raisons de cet état de fait, liées à la nature particulière des champignons euxmêmes. Nous présenterons ensuite un inventaire, non exhaustif et limité aux espèces indiscutables quant à leur implication dans le syndrome hallucinogène et quant à la présence de molécules psychoactives dans leurs sporophores

\section{Pourquoi est-il si difficile de produire une liste des champignons hallucino- gènes ?}

\section{1 - Caractère capricieux de l'apparition des sporo- phores}

Si l'on souhaite réaliser l'inventaire des espèces fongiques d'une zone géographique donnée, il faudra une patience considérable : les sporophores (appareil reproducteur, portant les cellules fertiles), seuls témoins de la présence d'un champignon, ne se montrent que lorsque les conditions, climatiques en particulier, le permettent. Des éclipses très longues peuvent survenir dans la vie des champignons, pendant lesquelles il n'est plus possible d'en déceler la présence alors qu'ils continuent à jouer leur rôle fonctionnel dans l'écosystème.

\section{2 - Difficultés d'identification}

Cherche-t-on à déterminer précisément une espèce ? Tout d'abord, cela n'est possible que par l'examen de ces fameux sporophores, capricieux et erratiques. Dans bien des cas, il faudra avoir acquis une solide expérience pour résoudre certains problèmes épineux, s'y retrouver dans les nombreuses publications, parfois contradictoires, qui se succèdent depuis deux siècles. Il faudra aussi disposer d'un microscope et maîtriser les techniques d'observation de structures parfois ténues ou inconstantes. Une identification fiable ne peut s'obtenir qu'après beaucoup d'efforts.

\section{3 - Problèmes de nomenclature}

Les difficultés ne s'arrêtent pas là. L'attribution d'un nom correct, une fois la détermination réalisée, demande encore de nouvelles qualités. Il faudra être capable de comprendre ou d'interpréter les règles du code international de nomenclature botanique (texte réglementaire, qui édicte les normes selon lesquelles un seul et unique nom correct doit désigner un taxon donné). Cet art de la dénomination est important, car il s'agit de pouvoir communiquer avec d'autres scientifiques et d'éviter les ambiguités qui gêneraient la compréhension et la comparaison de travaux, par exemple dans les domaines de la chimie ou de la toxicologie. 


\section{4 - Caractère fragmentaire des connaissances}

Un dernier élément semblera étonnant pour les non mycologues : des espèces nouvelles sont régulièrement découvertes par les chercheurs. Pour la seule année 2003, par exemple, au moins trois espèces de Psilocybe hallucinogènes ont été décrites pour la première fois : Psilocybe moravica (55) en République tchèque, Psilocybe galleciae (56) en Espagne, et Psilocybe atlantis (57) aux États-Unis. Ces découvertes incessantes contribuent à rendre plus floues les limites d'une éventuelle liste des espèces hallucinogènes.

Enfin, après leur création par un descripteur initial, certaines espèces ne sont pas retrouvées avant de nombreuses années. Entre temps, elles peuvent sembler être des espèces fantômes ou les contours de leur définition peuvent devenir assez flous. C'est ainsi que quelques psilocybes sud-américains (dans la liste ci-dessous) sont dits «à préciser», car non revus ou mal délimités dans le cadre des connaissances actuelles.

\section{5 - Comment définir une espèce hallucinogène?}

Pour le cas précis des espèces hallucinogènes, d'autres complications surgissent. Ce problème est abordé par Guzmán (58) qui rappelle que certains auteurs considèrent des polypores renfermant de l'hordénine, de la $\mathrm{N}$ méthyltyramine ou de la tyramine, comme des champignons à propriétés neurotropes. Or, ce sont des espèces assez anodines, provoquant parfois quelque ivresse légère suite au métabolisme de ces substances dans l'organisme, mais considérées et utilisées comme espèces comestibles dans certains pays. On intègre aussi parfois les espèces contenant des alcaloïdes du groupe de l'acide lysergique (ergot de seigle et autres espèces) ou de l'acide iboténique (quelques amanites, en particulier) parmi les champignons hallucinogènes, ou encore d'autres espèces utilisées dans des rites particuliers, dans diverses parties du monde (des bolets et des russules par exemple).

Nous limiterons ici strictement les espèces responsables du syndrome hallucinogène à celles qui renferment des dérivés indoliques particuliers : la psilocine et la psilocybine avec, pour certaines d'entre elles, la présence de baeocystine et/ou de norbaeocystine, précurseurs de la psilocybine.

\section{6 - Fiabilité des déterminations du matériel étudié par les toxicologues}

Certains chercheurs ont centré leurs activités sur ces deux molécules, en les traquant dans les sporophores d'espèces supposées responsables d'intoxications hallucinatoires ou de taxons voisins (espèces proches dans la classification). Ces investigations précises sont pertinentes à la condition que les espèces analysées soient déterminées de manière irréprochable. Dans le cas contraire, on risque d'attacher à une espèce anodine une étiquette non méritée et de la rendre suspecte à tort. Or, nous avons rappelé les difficultés liées à la pratique de la détermination mycologique. Guzmán. (58) rapporte même que des échantillons qui avaient été analysés dans le but d'isoler de la psilocybine, puis conservés en herbier, comprenaient en fait, ce qu'a révélé une expertise taxinomique autorisée, un mélange de différentes espèces! Dans le même ordre d'idée, des chercheurs travaillant sur deux continents différents et suivant des ouvrages de détermination identiques (ce qui est fréquent) peuvent nommer de la même manière deux espèces vicariantes, qui ont toutes les chances d'être chimiquement différentes. Cet autre piège est souvent négligé. Les collaborations sont nécessaires entre spécialistes des différentes disciplines en cause, ce qui n'a pas toujours été le cas (59). Les principaux caractères utilisés en pratique sont d'ordre macroscopique (voir Planche 1), microscopiques (voir Planche 2) et chimiques (40) : réactions macrochimiques sur les sporophores, ou microchimiques dans des préparations microscopiques en milieux spéciaux. L'aspect moléculaire commence à être envisagé aujourd'hui $(60,61)$.

\section{7 - Variabilité métabolique intraspécifique}

Une analyse ponctuelle n'est rien. Repke (62) ainsi que Gross $(47,48)$ ont mis en évidence des variations de composition chimique en fonction de l'âge des sporophores (jeunes individus ou spécimens plus vieux). Les capacités synthétiques de différentes souches d'une même espèce peuvent aussi varier selon le substrat colonisé, le climat et les conditions environnementales subies. Ceci est vraisemblablement le cas de populations d'un seul et même pays mais des variations importantes ont été démontrées d'un continent à l'autre. C'est d'ailleurs une des raisons pour lesquelles certaines espèces indiquées comme hallucinogènes, sur la base de leur composition chimique, sont ensuite disculpées par d'autres chercheurs : en fait, les échantillons analysés, provenant de régions très différentes, ne possèdent pas les mêmes propriétés chimiques ! C'est le cas de deux espèces au moins de Panaeolus, analysées sur des récoltes européennes, inactives, et sud-américaines, psycho-actives (63). Par ailleurs, les variations chimiques se poursuivent après dessiccation (ce qui peut influencer les effets attendus par d'éventuels consommateurs) et peuvent aboutir à la disparition des substances psychoactives (64), disparition qui semble à peu près totale après une année de conservation. Pourtant, Christiansen et coll. (65) ont indiqué avoir encore trouvé des quantités assez importantes de substances actives dans de vieux spécimens secs de Psilocybe semilanceata. Quant au processus de disparition de ces molécules, elles pourraient être volatiles, 

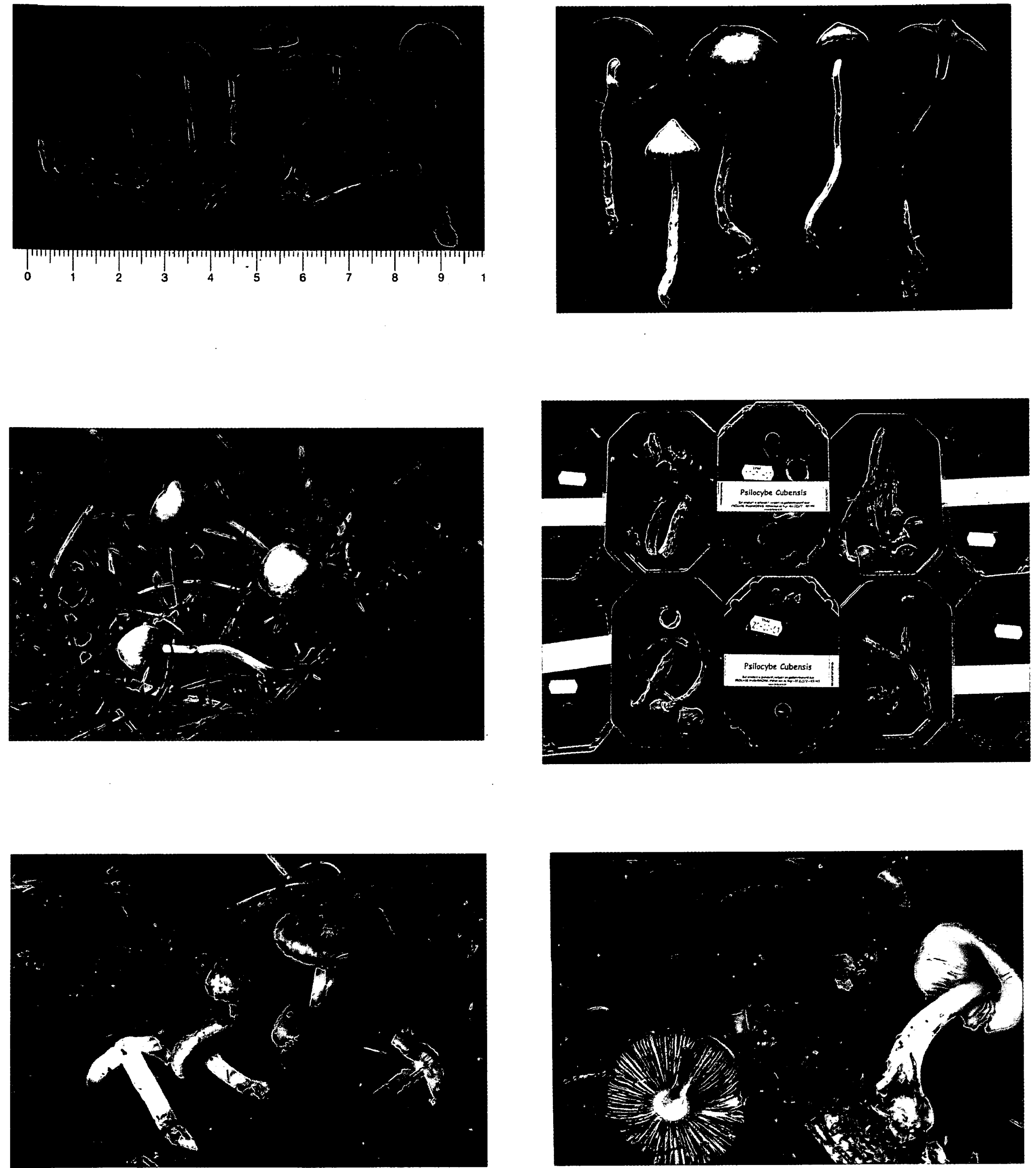

\section{Planche 1 : Vues macroscopiques.}

1 - Psilocybe fimetaria : Nord. Octobre 2002. Photo R. Courtecuisse

2 - Psilocybe strictipes : Vendée. Novembre 1989. Photo J. Vast

3 - Psilocybe semilanceata : Somme. Novembre 1993. Photo J. Vast

4 - Psilocybe subcubensis : barquettes étiquetées P. cubensis, issues d'une saisie policière (Nord, Mai 200I). Photo R. Courtecuisse

5 - Inocybe haemacta : Seine-Maritime. Octobre 1991. Photo J. Vast

6 - Pluteus salicinus : Morbihan. Sans date. Photo P. Boisselet. 


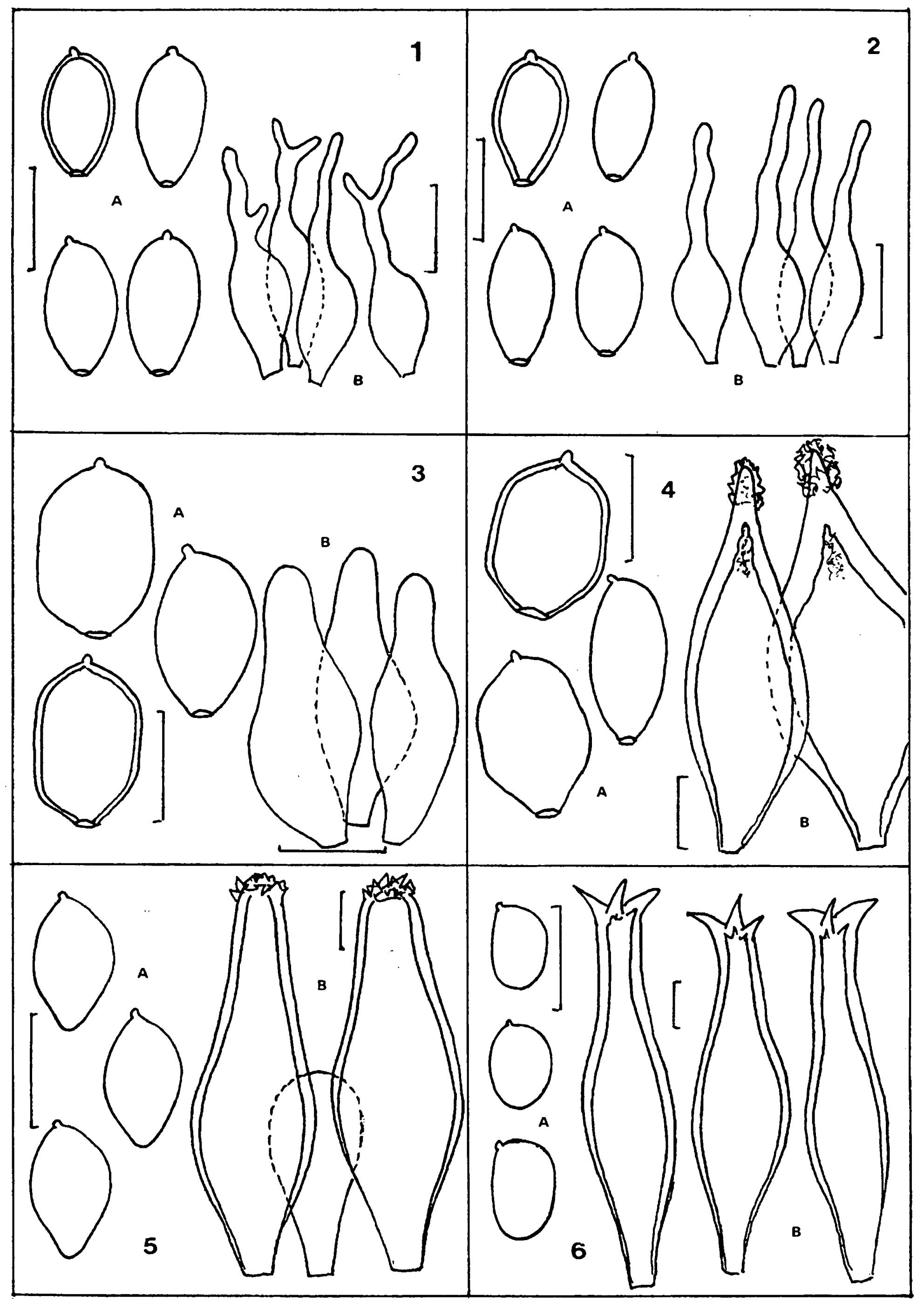

Planche 2 : Dessins microscopiques (R. Courtecuisse). Barre d'échelle $=10 \mu \mathrm{m}$.

$I$ - Psilocybe semilanceata ( $a:$ spores $; b$ : cheilocystides)

2 - Psilocybe fimetaria ( $a:$ spores; $b$ : cheilocystides)

3 - Psilocybe subcubensis ( $a:$ spores $; b$ : cheilocystides)

4 - Panaeolus cyanescens ( $a$ : spores; $b$ : cheilocystides)

5 - Inocybe haemacta ( $a:$ spores $; b:$ cystides oxalifères avec une paracystide intercalée)

6 - Pluteus salicinus ( $a$ : spores $; b$ : cystides à crochets) 
si on en croît l'expérience racontée par Guzmán (58), qui a ressenti personnellement les effets hallucinogènes d'espèces 'de Psilocybe, alors qu'il passait une nuit dans un lieu où de grandes quantités de spécimens récoltés dans la journée avaient été entreposées.

Ce sont donc des problèmes liés aux difficultés de détermination, aux variations chimiques intraspécifiques, à la méconnaissance de spécificités mycologiques de la part de certains chimistes, qui conduisent à cette difficulté d'établir une liste des espèces effectivement hallucinogènes.

\section{Les espèces hallucinogènes d'Europe et des Amériques.}

On trouve plusieurs sites sur l'Internet présentant des listes d'espèces de champignons renfermant de la psilocybine. La plupart semblent fantaisistes et, le plus souvent, aucune référence bibliographique ne vient étayer les données présentées (par exemple «187 espèces à psilocybine» sont listées sur le site http://www.mushroomjohn.com/listedspecies1.htm, 101 espèces sur le site http://leda.lycaeum.org, un peu plus restrictif). Quelques tentatives de mise au point ont été publiées, à l'échelle mondiale, en particulier par Guzmán $(58,66)$ et à l'échelle européenne (4). Ces derniers travaux, citant des références bibliographiques effectives, présentent des listes qui semblent encore trop larges, certaines espèces citées n'ayant pas fait l'objet d'analyses répétées ni contradictoires et d'autres, au contraire étant maintenues dans les listes malgré des publications ayant démontré qu'une inscription initiale avait été fondée sur des erreurs de différentes natures. Nous présentons donc une nouvelle liste plus restrictive, en éliminant les taxons les plus douteux. Elles est donnée dans l'Annexe 1.

D'un point de vue strictement mycologique, il est remarquable de constater que pratiquement toutes les espèces que l'on peut citer ici sont des Cortinariales. Seules trois d'entre elles appartiennent à l'ordre des Plutéales (67). Le genre Psilocybe offre assez peu de problèmes car la présence des molécules impliquées dans le syndrome hallucinogène suit parfaitement le cadre systématique, certaines sections pouvant être intégralement versées dans cette liste (même s'il s'agit de spéculation pour certaines espèces qui n'ont jamais été analysées, ce classement semble tout à fait crédible). Par contre, les autres genres sont plus difficiles à trier, sans doute en raison de plus grandes variations chimiques selon les souches étudiées et leur origine géographique. Le genre Panaeolus illustre parfaitement ce problème (en supposant que les connaissances taxinomiques soient suffisamment avancées pour ne pas assimiler des taxons vicariants, qui devraient être séparés) par l'existence supposée de souches américaines psychoactives alors que les souches européennes le seraient moins ou pas du tout (d'où les contradictions trouvées dans la littérature). D'autres genres sont dans le même cas, en particulier les Gymnopilus.

Pour chaque espèce citée dans la liste, le nom correct, avec auteurs et lieu de publication, est complété par les informations suivantes :

= Réf. = référence $(\mathrm{s})$ citant l'espèce comme hallucinogène.

- Rép. = répartition géographique connue (références citées ou données issues des travaux préliminaires de R. Courtecuisse sur une check-list européenne, en cours).

- Écol. = écologie.

- Dos. = données quantitatives sur la psilocybine et la psilocine (éventuellement baeocystine et norbaeocystine). Sauf mention contraire, les pourcentages sont donnés par rapport à la matière sèche.

- Rem. = éventuelles remarques complémentaires.

Les espèces pour lesquelles des données analytiques effectives existent sont inscrites en caractères gras. Les autres, non analysées et dans lesquelles ces molécules n'ont pas été mises en évidence, sont présentées sur la base de critères taxinomiques (proximité avec une ou plusieurs espèces hallucinogènes ou appartenance à une section renfermant de telles espèces), morphologiques (en particulier le bleuissement de la chair, caractère commun à toutes les espèces comportant ces molécules ou presque (68), auquel s'ajoute souvent une odeur farineuse) ou ethnologiques (effets psychotropes constatés après ingestion par des expérimentateurs de différentes natures, ou usages traditionnels ou récréatifs constatés).

Après chaque taxon (ordres, familles, genres), le nombre d'espèces hallucinogènes est indiqué. Les références citées dans les rubriques «Rép.», «Écol.» et «Dos.» de cette liste renvoient à l'Annexe 2, constituée par une bibliographie extensive rédigée selon les normes en vigueur dans les revues scientifiques de mycologie.

\section{Bilan général}

La liste que nous avons élaborée rassemble 129 espèces sur les continents européen et américain, que l'on peut considérer, plus ou moins sûrement, comme hallucinogènes. $\mathrm{Ce}$ chiffre se décompose comme suit : 49 espèces présentant avec certitude un au moins des composants hallucinogènes (psilocybine ou psilocine, éventuellement accompagné(s) d'un de ses précurseurs, la baeocystine ou la norbaeocystine) ; 80 espèces non analysées, pour lesquelles on ignore si la psilocybine ou l'un des composants indoliques proches est 
présent ou non, mais qui montrent une parenté systématique suffisante pour être fortement suspectées ou qui sont utilisées dans le cadre de cérémonies religieuses ou de pratiques toxicomaniques dans leurs pays d'origine. Vingt espèces, douteuses pour différentes raisons, le plus souvent liées à des contradictions dans la littérature ou à des problèmes taxinomiques complexes, voire à des erreurs d'identification possibles, sont néanmoins maintenues, portant le total maximal à 149. Quelques taxons classiquement retenus ont été écartés, suite à de très sérieuses mises en doute des données initiales.

Si ce chiffre final est relativement important, il est moins élevé que dans certains documents qui circulent sur l'Internet ou dans la littérature spécialisée. Il restera cependant à compléter cette liste avec les espèces asiatiques (Inde, Japon, Thaïlande, Viet-Nam, Cambodge, etc.), océaniques (Australie, NouvelleZélande, en particulier) et africaines (présentes de l'Afrique du Nord à l'Afrique du Sud !). Ces dernières sont moins nombreuses, la grande majorité des champignons hallucinogènes étant américains. On peut penser qu'une vingtaine d'espèces extra-européennes et non-américaines viendraient allonger cette énumération, et que celle-ci atteindrait probablement un chiffre situé aux alentours de 180 espèces, à l'échelle mondiale.

\section{Conclusion}

Les principaux champignons hallucinogènes d'Europe sont Psilocybe semilanceata et Paneolus cinctulus, eut égard à leur fréquence et à leurs teneurs en psilocybine et en psilocine. En revanche, il est extrêmement difficile de préciser les espèces les plus fréquemment mises en cause en Amérique du Nord et en Amérique Centrale, eut égard aux aspects ethnologiques fortement ancrés dans ces continents. Si en Europe ces champignons sont uniquement consommés dans un but récréatif, l'aspect ethnologique existe bel et bien dans les Amériques. On peut raisonnablement penser qu'il existe au maximum 150 espèces de champignons hallucinogènes en Europe et dans les Amériques. A l'échelle mondiale, ce chiffre devrait se situer aux alentours de 180 espèces. Pour établir ces listes avec certitude, un autre travail reste à effectuer : rechercher et doser systématiquement les dérivés indoliques à effets hallucinogènes et/ou leurs précurseurs ; analyser systématiquement, à l'occasion de nouvelles récoltes de matériel faites dans le cadre de missions mycologiques dans les pays tropicaux, les spécimens appartenant à des espèces suspectes pour le moment. Cela permettrait de confirmer certains soupçons et d'objectiver progressivement les limites de cette liste. Ainsi disparaîtrait peu à peu le flou mycologique à l'origine de difficultés pour qualifier le caractère hallucinogène d'un champignon et donc du flou législatif et réglementaire.

Le principal problème toxique posé par les champignons hallucinogènes reste cependant les confusions possibles avec des champignons vénéneux $(4,18)$ : syndrome phallö̈dien avec Galerina autumnalis et d'autres champignons du genre Galerina, syndrome muscarinien avec les Inocybe. Il faut y ajouter la cardiotoxicité de la phényléthylamine parfois présente dans Psilocybe semilanceata (69). Les anglo-saxons ont en effet la mauvaise habitude de récolter tous les petits champignons bruns (little brown mushrooms, LBM), espérant y trouver des traces de produits psychoactifs.

\section{Références}

1. Karch S.B. Hallucinogens. In : Karch S.B. (ed.) Pathology of drugs of abuse. Boca Raton : CRC Press, 2002 ; 302-6.

2. Benitez F. Les champignons hallucinants. Paris : Editions du Lézard, 1995 ; 110 pp.

3. Djilani M., Bureau F. Champignons. In : Richard D., Senon J.L. (ed.) Dictionnaire des drogues, des toxicomanies et des dépendances. Paris : Larousse-Bordas, 1999 ; 83-5.

4. Deveaux M., Courtecuisse R., Gosset D. Champignons hallucinogènes d'Europe : aspects botaniques et toxicologiques. Toxicorama $1998 ; 10$ (2) : 80-4.

5. Wasson R.G. Seeking the magic mushrooms. Life 1957 , May $13 ; 42: 100-20$.

6. Heim R., Wasson R.G. Les champignons hallucinogènes du Mexique. Paris : Editions du Muséum d'histoire naturelle, 1958.

7. Rapport annuel sur l'état du phénomène de la drogue dans l'Union européenne et en Norvège. Luxembourg : Office des publications officielles des Communautés européennes, 2003.

8. Granger B. Les substances hallucinogènes. In : Fénelon G., Cambier J., Widlöcher D. (ed.) Hallucinations, regards croisés. Paris : Masson, 2002 ; 213-24.

9. Aversenq C. Psilocybe semilanceata, une toxicomanie particulière; enquête auprès des usagers du pays Màssatois. Thèse Doct. Médecine, Toulouse, 2000.

10. Bogusz M.J., Maier R.D., Schaefer A.T., Erkens M. H. Honey with Psilocybe mushrooms: a revival of a very old preparation on the drug market? Int. J. Legal Med. $1998 ; 11: 41-3$.

11. Brande E. A poisonous species of Agaric. Med. Phys. $1799 ; 11: 41-3$.

12. Gartz J. Narrenschwämme. Psychotrope Pilze in Europa. Herausforderung an Forschung und Wertsystem. Berlin, Basel : Heuwinkel, 1990 ; 136 pp.

13. Shulgin A., Shulgin A. Pihkal : a chemical love story. Berkeley: Transform Press, 1995 ; 230-9.

14. Shulgin A., Shulgin A. Tihkal : the continuation. Berkeley: Transform Press, 1997 ; 468-73. 
15. Quetin A.M. La psilocybine en psychiatrie clinique et expérimentale. Thèse Doct. Pharmacie, Paris, 1960.

16. Peden N.R., Bisset A.F., Macaulay K.E.C. Clinical toxicology of "magic mushrooms" ingestion. Postgr. Med. J. $1981 ; 57: 543-5$.

17. Leikin J.B., Krantz A.J., Zell-Kanter M. Clinical features and management of intoxication due to hallucinogenic mushroom. Med. Toxicol. Adv. Drug Exp. 1989 ; 4 : 32450.

18. Seivewright $N$., Lagundoye $O$. What the clinician needs to know about magic mushrooms. Adv. Psych.. Treatment $2000 ; 6: 344-7$.

19. Sivyer C., Dorrington L. Intravenous injection of mushrooms. Med J. Aust. 1984 ; 140 (3) : 182.

20. Borowiak K.S., Ciechanowski K., Waloszczyk P. Psilocybin mushroom (Psilocybe semilanceata) intoxication with myocardial infraction. Clin. Toxicol. $1998 ; 36$ (1\&2) : 47-9.

21. Franz M., Regele H., Kirchmair M. magic mushrooms: hope for a "cheap high" resulting in end-stage renal failure. Nephrol. Dial. Transplant. 1996 ; 11 : 2324-7.

22. Raff E., Halloran P.F., Kjellstrand C.M. Renal failure after eating "magic" mushrooms. Can. Med. Assoc. J. $1992 ; 147: 1339-41$.

23. Vincent F. Hallucinogènes. In : Kintz P. (coordinateur) Toxicologie et pharmacologie médico-légales. Paris: Elsevier Option Bio, 1998 ; 569-74.

24. Abraham H.D., Aldridge M.B., Gogia P. The psychopharmacology of hallucinogens. Neuropsychopharmacol. $1996 ; 14: 285-98$.

25. Abraham H.D., Aldridge A.M. Adverse consequences of lysergic acid diethylamide. Addiction 1993 ; 88 : 1327 34.

26. Halpern J.H., Pope H.G. Hallucinogen persisting perception disorder: what do we know after 50 years? Drug Alchol Depend. 2003 ; 69 : 109-19.

27. Classification Internationale des Maladies (10ème version) CIM-10. Chapitre V. Troubles mentaux et troubles du comportement. Paris : Masson, 1993.

28. Hasler F., Bourquin D., Breneisen R., Baer T., Vollenweider F.X. Determination of psilocin and 4hydroxyindole-3-acetic acid in plasma by HPLC-ECD and pharmacokinetic profiles of oral and intravenous psilocybine in man. Pharm. Acta Helv. 1997 ; 72 : 175-84.

29. Hasler F., Bourquin D., Brenneisen R., Vollenweider F.X. Renal excretion profiles of psilocin following oral administration of psilocybin : a controlled study in man. J. Pharmac. Biomed. Anal. 2002 ; 30 : 331-9.

30. Gérault A., Picard T. Intoxication mortelle à la suite de la consommation volontaire et en groupe de champignons hallucinogènes. Bull. Soc. Mycol. Fr. 1996 ; 112 : 56-8.

31. Moffat A.C., Osselton M.D., Widdop B. Psilocin and psilocybine. In : Clarke's analysis of drugs and poisons in pharmaceutical, body fluids and postmortem material (3 $3^{\text {eme }}$ éd.). London : Pharmaceutical Press, 2004 ; 1506-7.

32. Asselborn G., Wennig R., Yegles M. Tragic flying attempt under the influence of "magic mushrooms". Problems of Forensic Sci. 2000 ; XLII : 41-6.

33. Schultes R.E., Hofmann A. Les plantes des dieux (traduction française) Paris: Editions du Lézard, 1993 ; 192 pp.
34. De Smet P.A.G.M. Some ethnopharmacological notes on african hallucinogens. J. Ethnopharmacol. 1996 ; 50 : 141-6.

35. Carlini E.A. Plants and the central nervous system. Pharmacol. Biochem. Behav. 2003 ; 75 : 501-12.

36. Hofmann A., Frey A., Ott H., Petrzilla T., Troxler F. Konstitutionaufklärung und Synthese von Psilocybine. Experientia $1958 ; 15: 397-9$.

37. Hofmann A. Heim R., Tscherter H. Présence de la psilocybine dans une espèce européenne d'Agaric, le Psilocybe semilanceata. C.-R. Acad. Sci. Paris. 1963 ; $257: 10-2$.

38. Gartz J. Biotransformation of tryptamine derivatives in mycelial cultures of Psilocybe. J. Basic Microbiol. $1989 ; 29$ (6) : 347-52.

39. Sticht G., Käferstein H. Detection of psilocin in body fluids. Forensic Sci. Int. $2000 ; 113: 403-7$.

40. Grieshaber A.F., Moore K.A., Levine B. The detection of psilocin in human urine. J. Forensic Sci. 2001 ; 46 (3) : 627-30.

41. Lindenblatt H., Krämer E. Holzmann-Erens P., Gouzoulis-Mayfrank E., Kovar K.A. Quantitation of psilocin in human plasma by HPLC and electrochemical detection: comparison of liquid-liquid extraction with automated on-line solid-phase extraction. J. Chromatogr. B Biomed. Sci. Appl.1998 ; 709 : 255-63.

42. Musshoff F., Madea B., Beide J. Hallucinogenic mushrooms on the German market - simple instructions for examination and identification. Forensic Sci. Int. 2000 ; $113: 389-95$.

43. Hasler F., Bourquin D.F., Brenneisen R.M., Bär T., Vollenweider F.X. Urine excretion profiles of psilocin following. oral administration of psilocybin. Communication presentée à : SOFT Annual Congress, Denver (USA) 1996.

44. Yamada F., Tamura M., Hasegawa A., Somei M. Synthetic studies of psilocin analogs having either a formyl group or bromine atom at the 5 - or 7-position. Chem. Pharm. Bull. 2002 ; 50 (1) : 92-9.

45. Anastos N., Barnett N.W., Lewis S.W., Gatherhood N.K.P., Scammels P.J., Sims N.D. Synthesis and detection of psilocin and psilocybin using flow injection analysis coupled with chemiluminescence detection. Communication presentée à : 41st International TIAFT meeting, Melbourne (Australie) 2003.

46. Albers C., Lehr M., Beike J., Köhler H., Brinkmann B. Synthesis of a psilocin hapten and a protein-hapten conjugate. J. Pharma. Pharmacol. 2002 ; 54 : 1265-70

47. Gross S.T. Detecting psychoactive drugs in the developmental stages of mushrooms. J. Forensic Sci. $2000 ; 45$ (3) : 527-37.

48. Gross S.T. Psychotropic drugs in developmental mushrooms: a case study review. J. Forensic Sci. $2002 ; 47$ (6) 1298-302.

49. Anonyme. Méthodes recommandées pour l'identification du peyotl et de la mescaline ainsi que des psilocybes et de la psilocybine. Manuel à l'usage des laboratoires nationaux de stupéfiants. ST/NAR 19, New York: Nations Unies, $1990 ; 21-45$.

50. Keller T., Schneider A., Regenscheidt P., Dirnhofer R., Rücker T., Jaspers J., Kisser W. Analysis of psilocybin and psilocin in Psilocybe subcubensis Guzman by ion 
mobility spectrometry and GC-MS. Forensic Sci. Int. 1999 ; 99 : 93-105.

51.Pedersen-Bjergaard S., Rasmussen K.E., Sannes E. Strategies for the capillary electrophoretic separation of indole alkaloids in Psylocybe semilanceata. Electrophoresis $1998 ; 19$ (1) : 27-30.

52.Pedersen-Bjergaard S., Sannes E., Rasmussen K.E., Tonnesen F. Determination of psilocybin in Psylocybe semilanceata by capillary zone electrophoresis. J. Chromatogr. B 1997 ; 694 : 375-81.

53. Schläpfer M., Bovens M. Hallucinogenic mushrooms: validated analysis of psilocin and psilocybin by MECC. Forensic Sci. Int. 2003 ; 136 (suppl.1) : 96.

54. Kysilka R. Determination of psolicin in rat urine by HPLC with electrochemical detection. J. Chromatrogr. 1990 ; 534 : 287-90.

55. Borovicka J. Modrající lysohlávky (Psilocybe) v Ceské republice. III. Psilocybe moravica sp. nova, lysohlávka moravská. Mykol. Sborn. 2003 ; 80(4) : 126-41.

56. Guzmán, G., Castro M.L. Observations on some known species of Psilocybe (Basidiomycotina, Agaricales, Strophariaceae) from Spain and description of a new species. Bol. Soc. Micol. Madrid 2003 ; 27 : 181-7.

57. Guzmán G., Hanlin R.T., White C. Another new bluing species of Psilocybe from Georgia, U.S.A. Mycotaxon $2003 ; 86: 179-83$.

58. Guzmán G., Allen J.W., Gartz J. A worldwide geographical distribution of the neurotropic fungi, an analysis and discussion. Ann. Mus. Civ. Rovereto, Sez. Archeol., Stor. e Sci. Nat. $2000 ; 14: 189-280$.

59. Smith A.H. Comments on hallucinogenic agarics and the hallucinations of those who study them. Mycologia $1977 ; 69: 1196-200$.
60. Lee J. C. I., Cole M., Linacre A. Identification of members of the genera Panaeolus and Psilocybe by a DNA test. A preliminary test for hallucinogenic fungi. Forensic Sci. Intern. $2000 ; 112: 123-33$.

61. Lee J. C. I., Cole M., Linacre A. Identification of hallucinogenic fungi from the genera Psilocybe and Panaeolus by amplified fragment length polymorphism. Electrophoresis $2000 ; 21$ : 1484-7.

62. Repke D.B., Leslie D.T. Baeocystin in Psilocybe semilanceata. J. Pharm. Sci. 1977 ; 66 : 113-4.

63. Stijve T. Worldwide occurrence of psychoactive mushrooms - an update. Czech Mycol. 1995 ; 48(1) : 11-9.

64. Ohenoja E., Jokiranta J., Maykinen T., Kaikkonen A., Airaksinen M.M. The occurrence of psilocybin and psilocin in Finnish Fungi. J. Nat. Products 1987 ; 50 : 7414.

65. Christiansen A.L., Rasmussen K.E. Analysis of indole alkaloids in norwegian Psilocybe semilanceata using high-performance liquid chromatography and mass spectroscopy. J. Chromatogr. $1982 ; 244$ : 357-64.

66. Guzmán G. The genus Psilocybe. A systematic revision of the known species including the history, distribution and chemistry of the hallucinogenic species. Beih. Nova Hedwigia $1983 ; 74: 439-50$.

67. Saupe S.G. Occurrence of psilocybin/psilocin in Pluteus salicinus (Pluteaceae). Mycologia 1981; 73: 781-4.

68 . Levine W. Formation of blue oxidation product from psilocybin. Nature $1967 ; 215: 1292-3$.

69. Beck O., Helander A., Karlson-Stiber C., Stephanson N. Presence of phenylethylamine in hallucinogenic Psilocybe mushroom: possible role in adverse reactions. J. Anal. Toxicol. $1998 ; 22: 45-9$. 


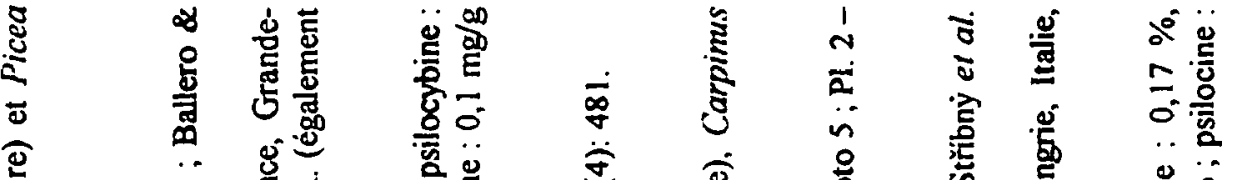

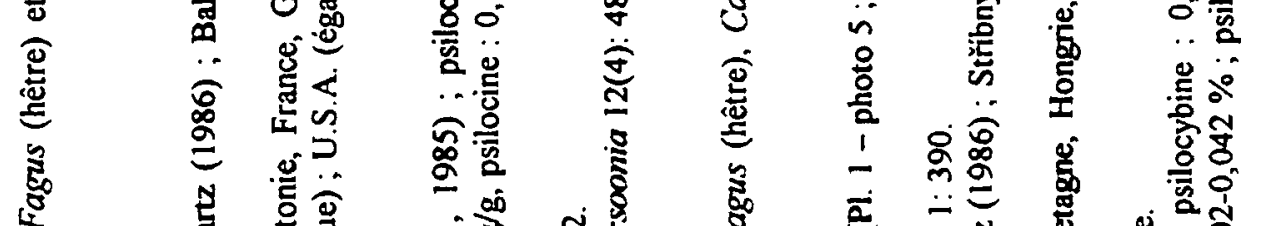

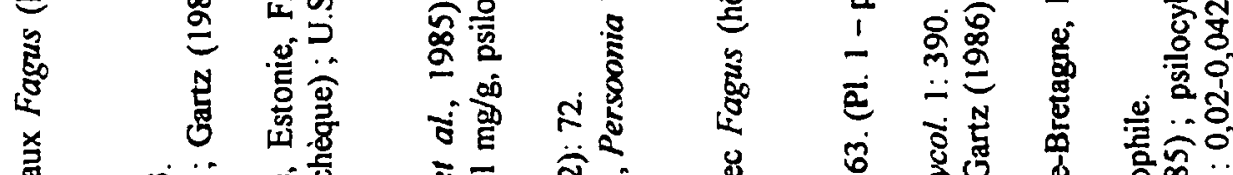

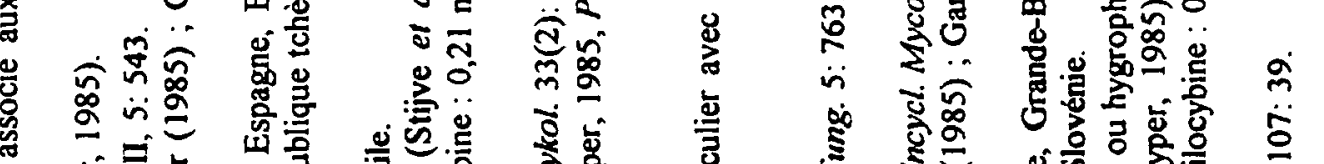

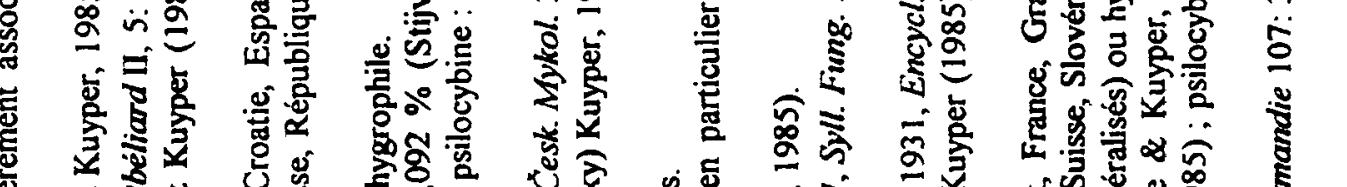

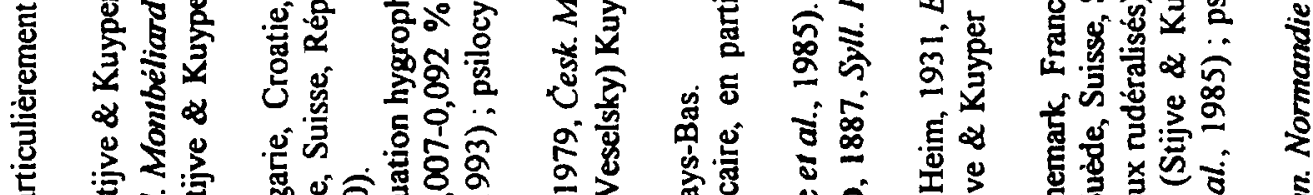

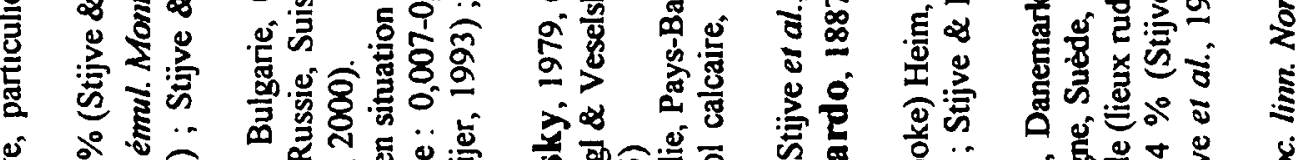

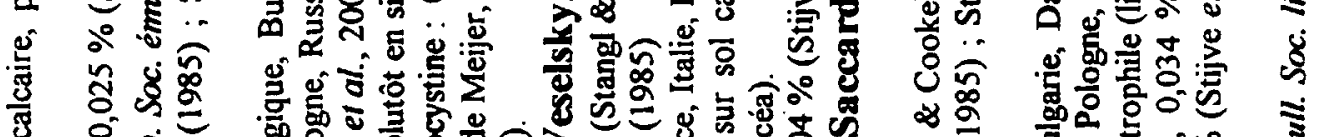

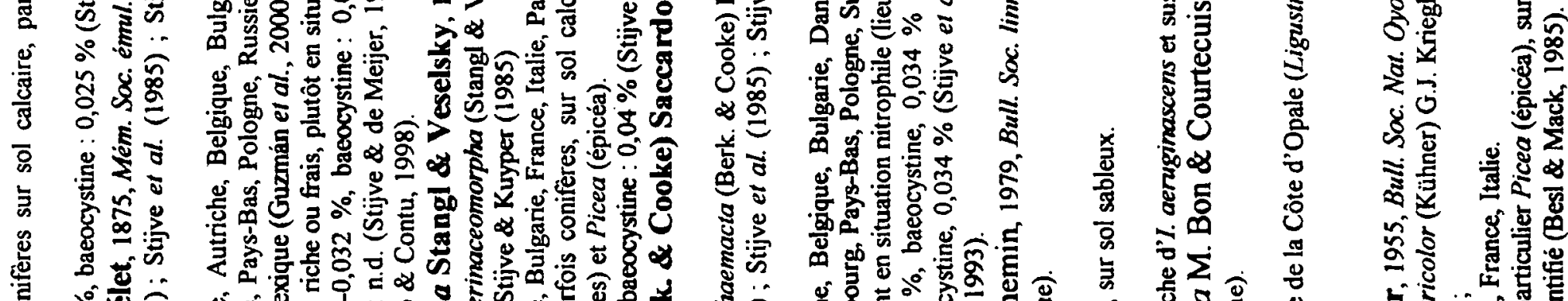

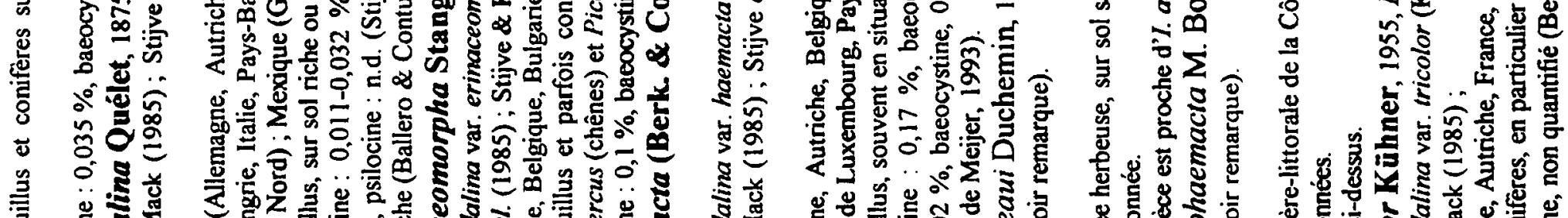

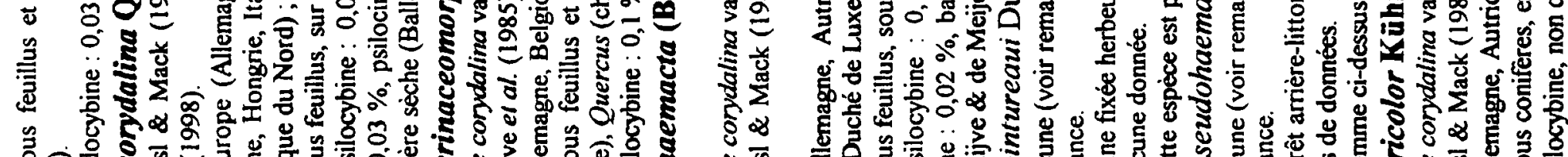

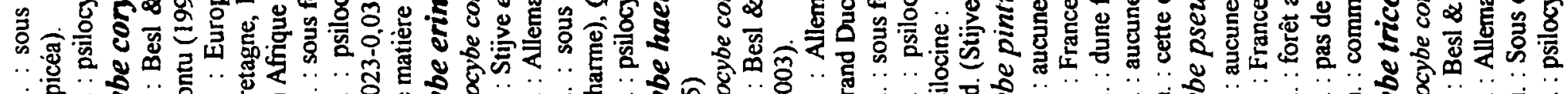

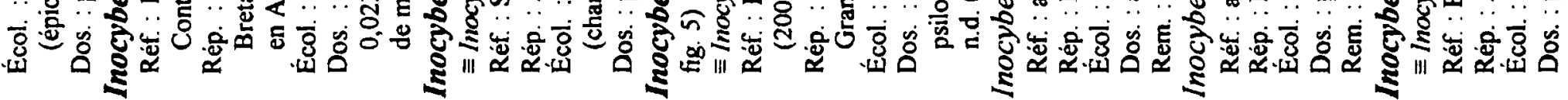
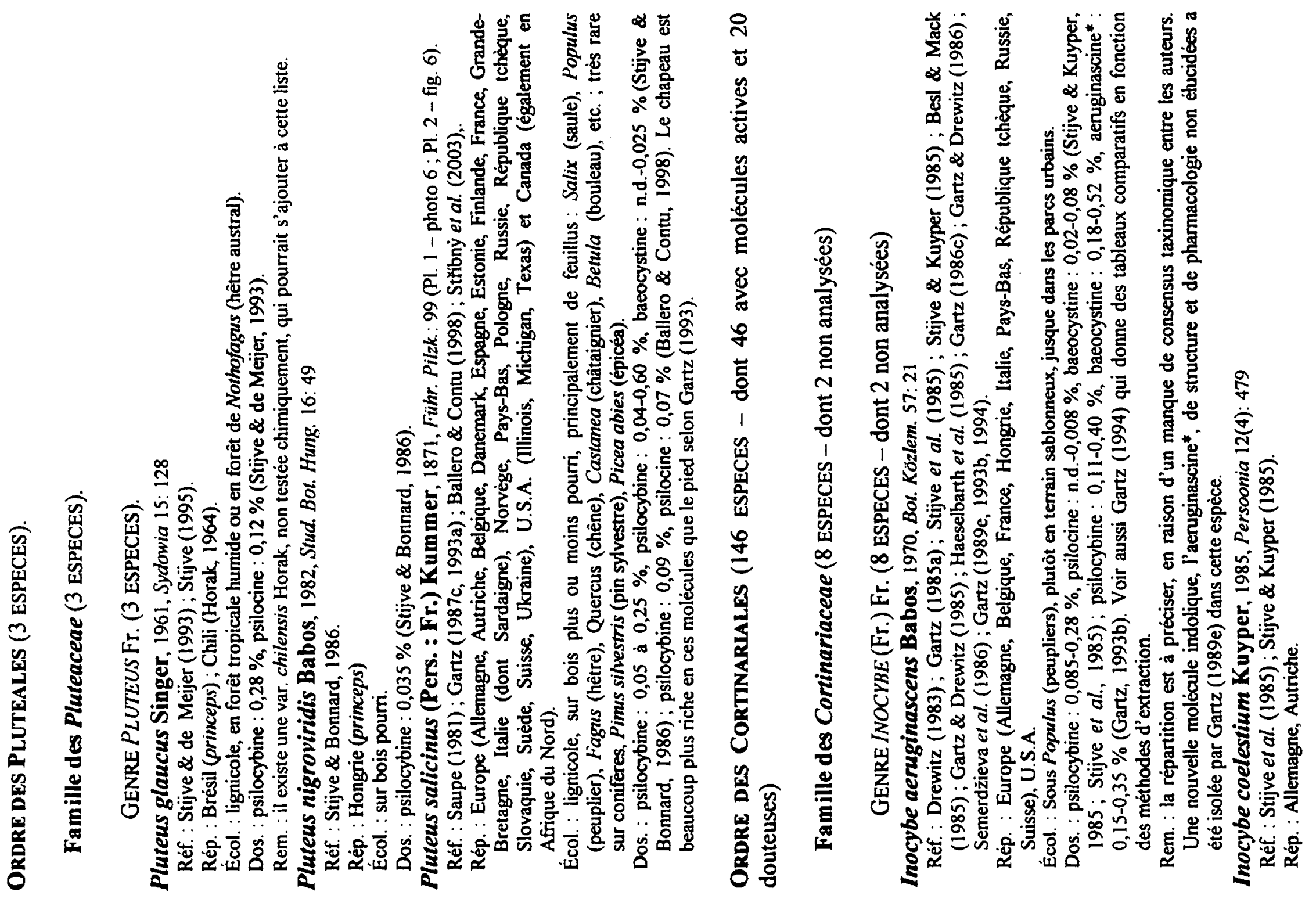

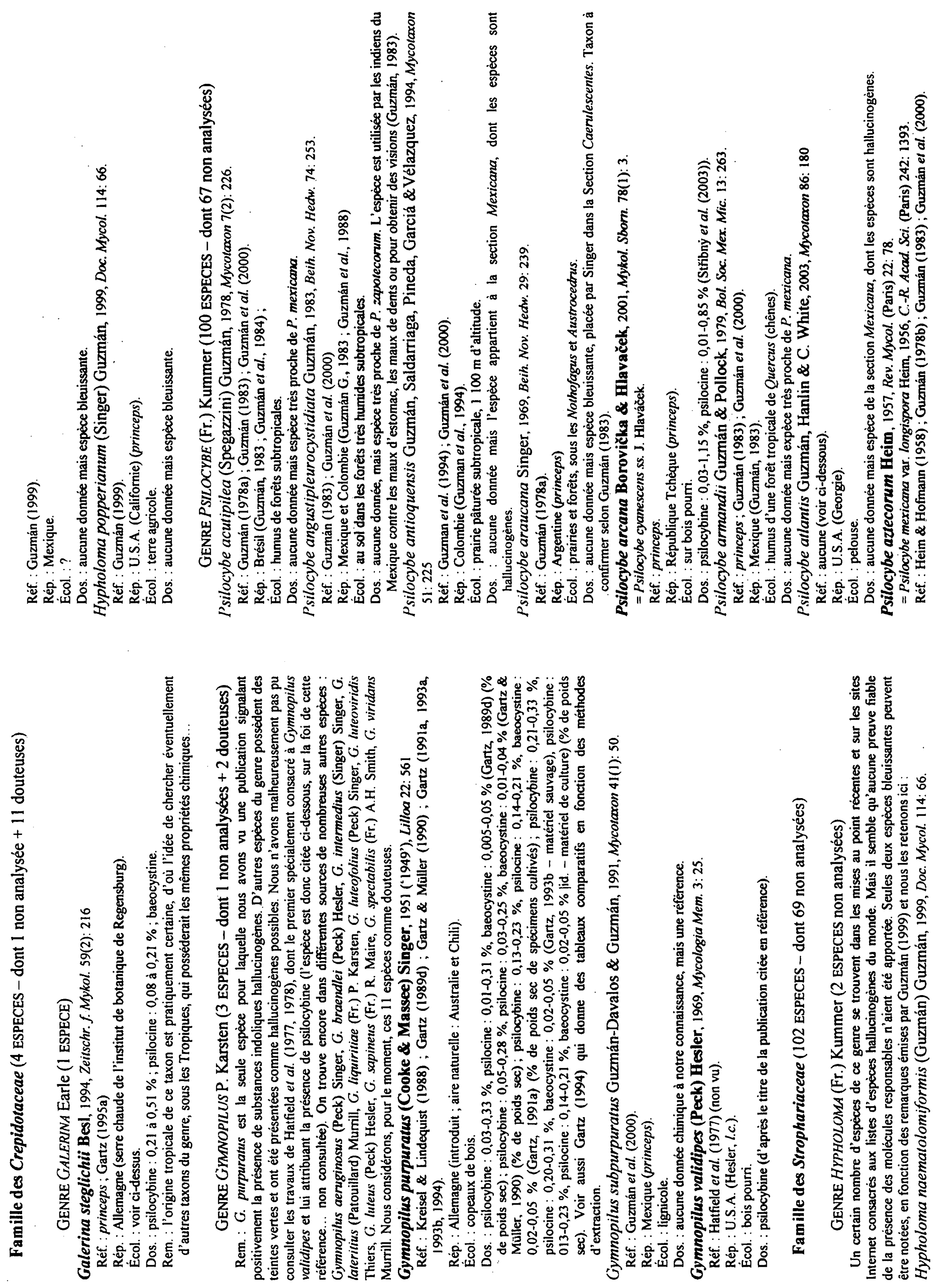

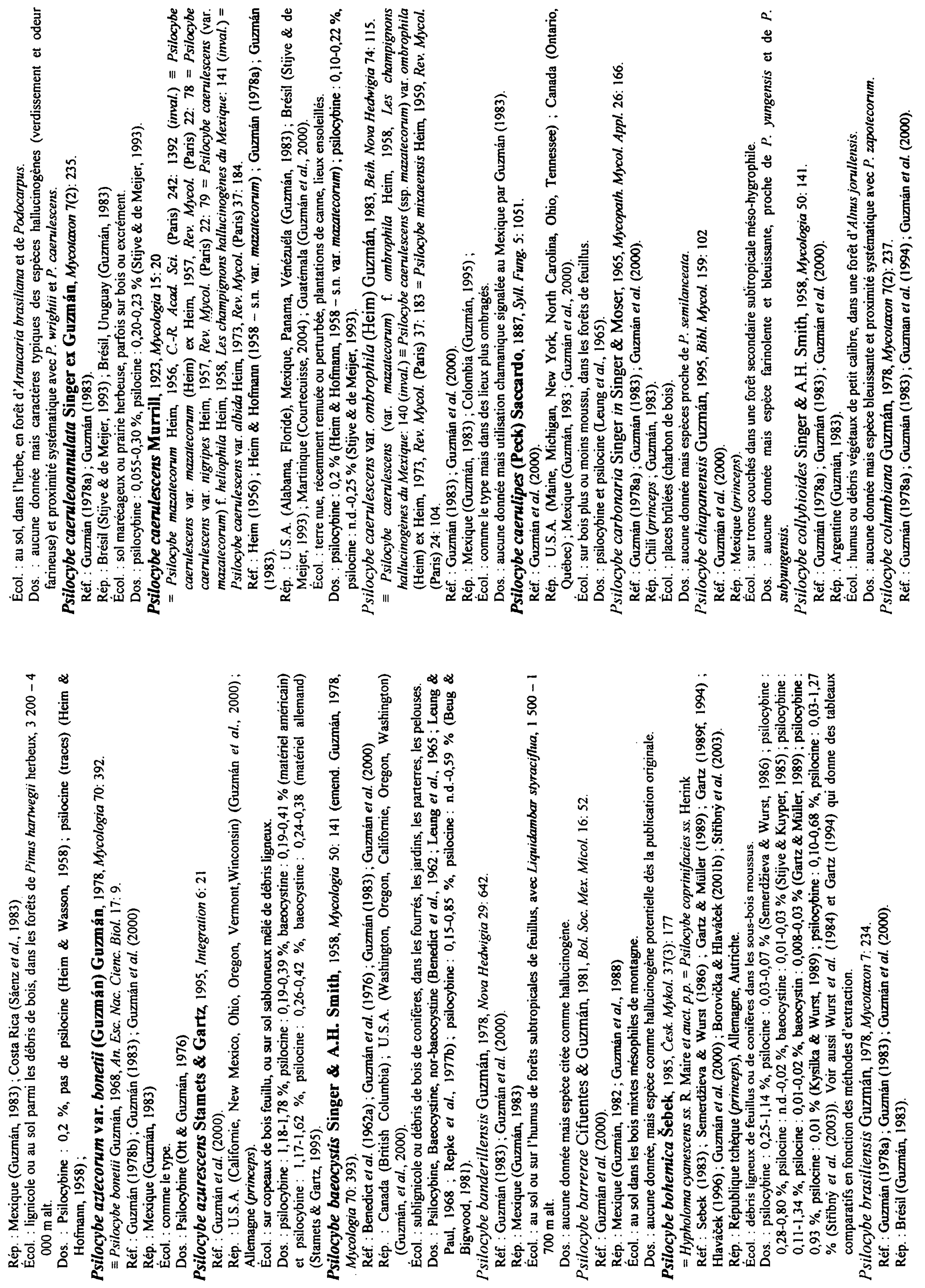

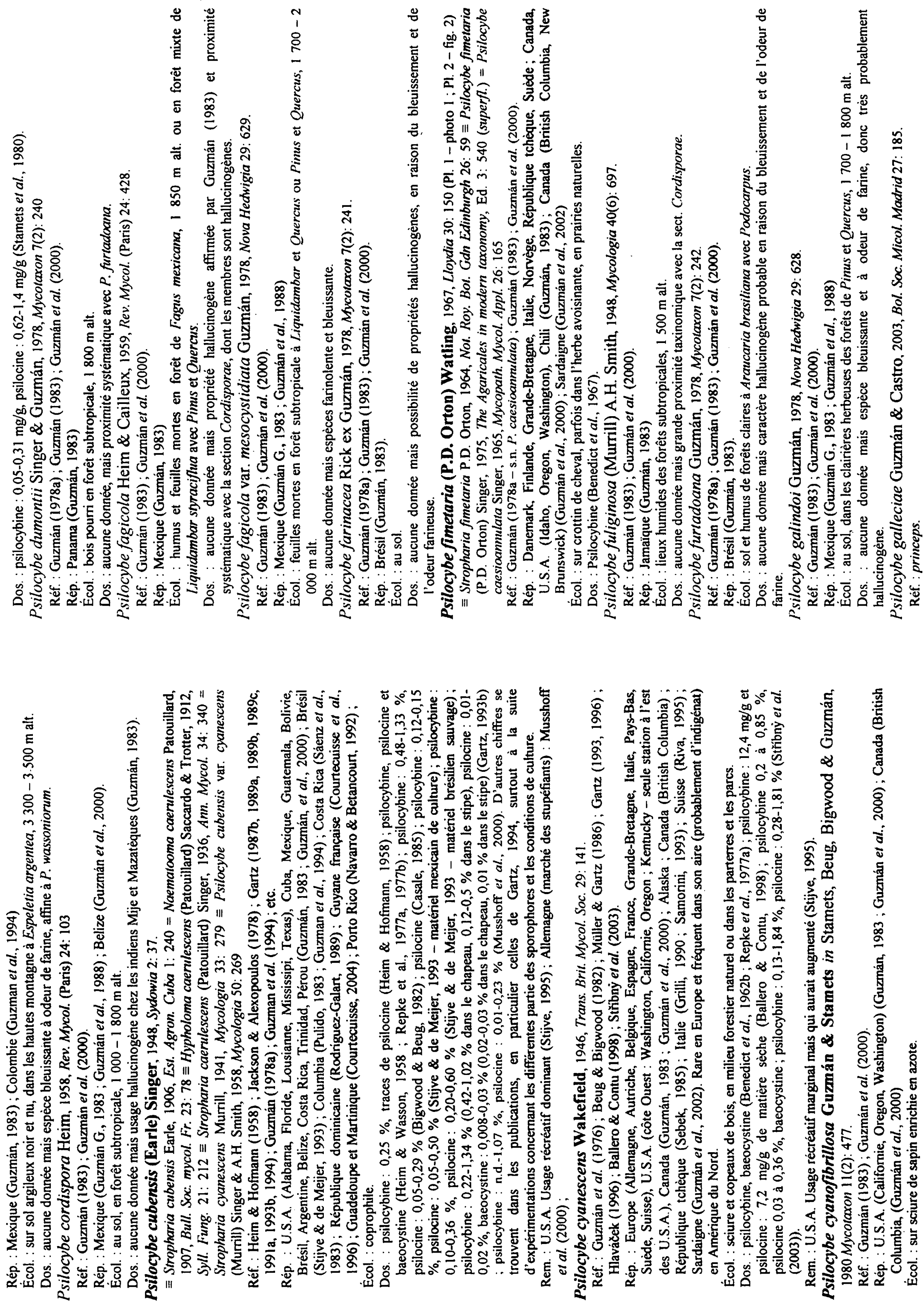



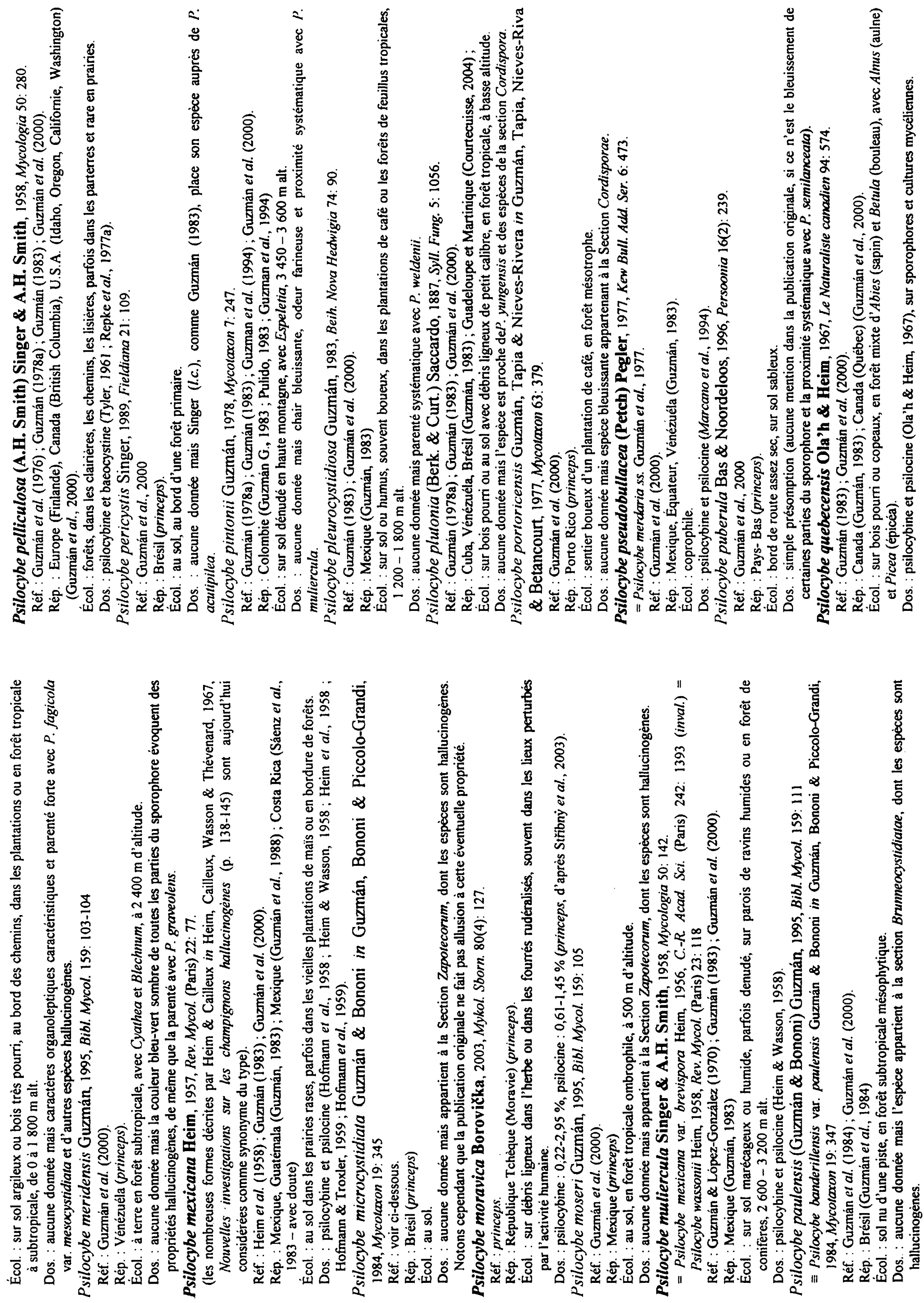



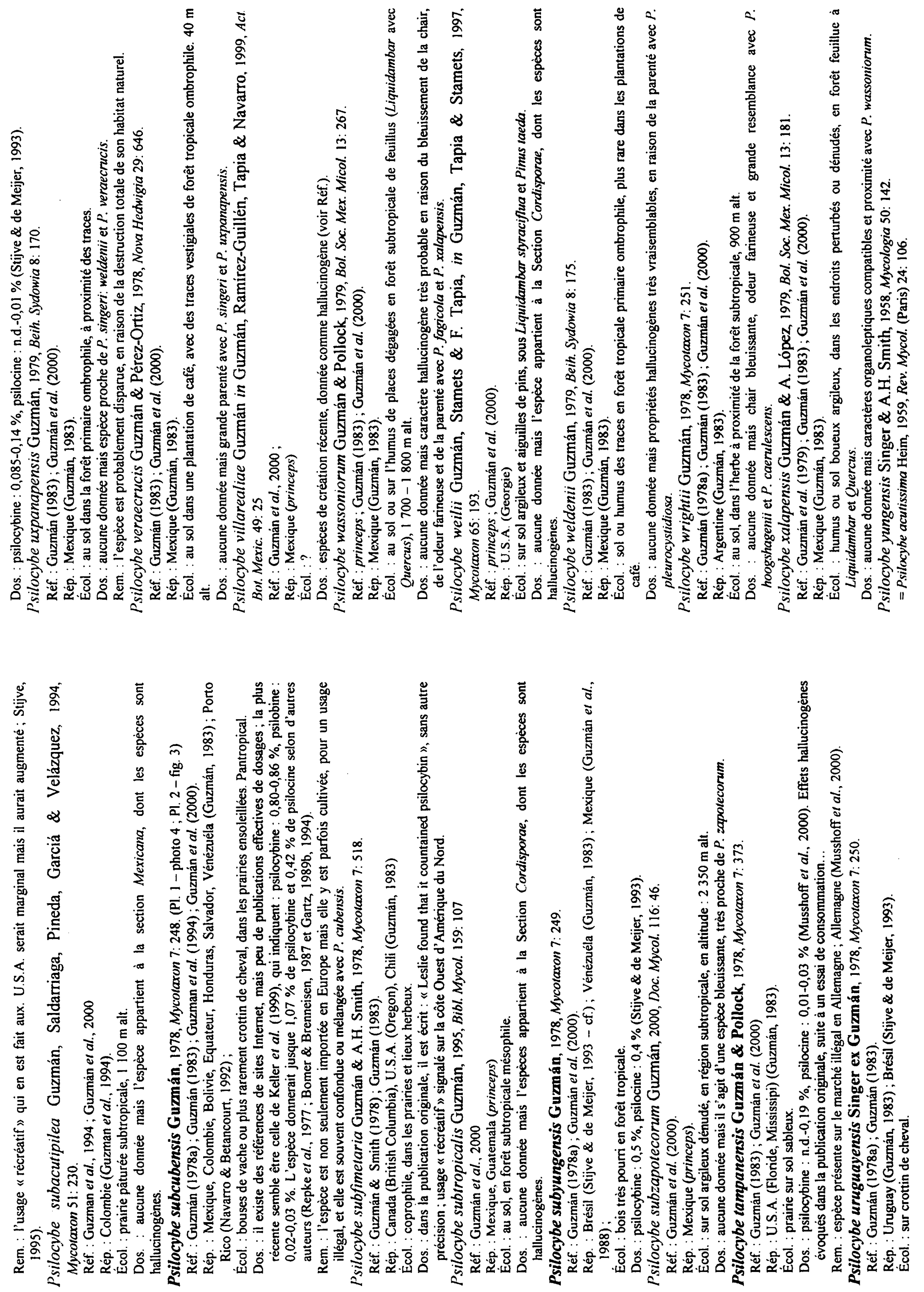




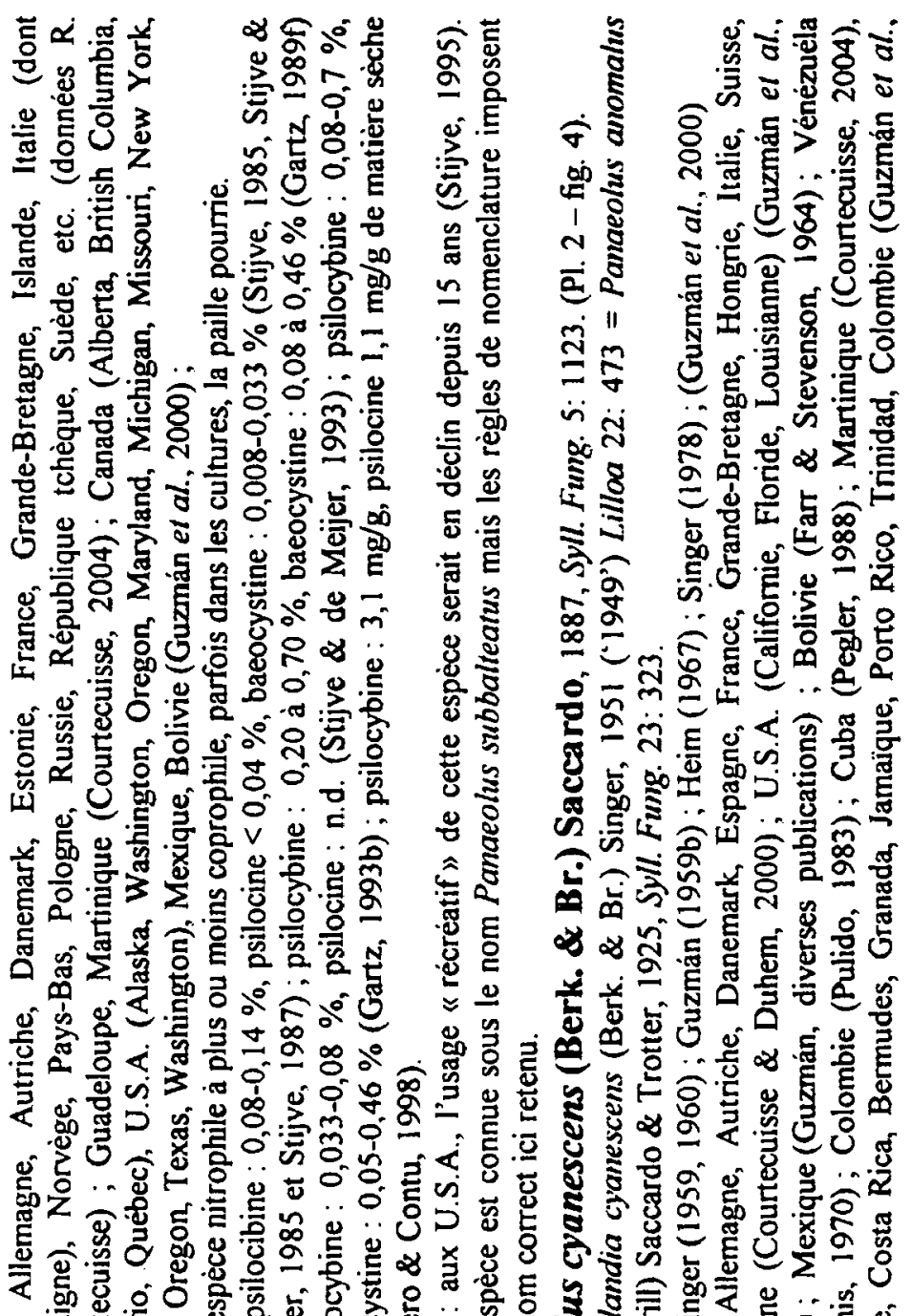
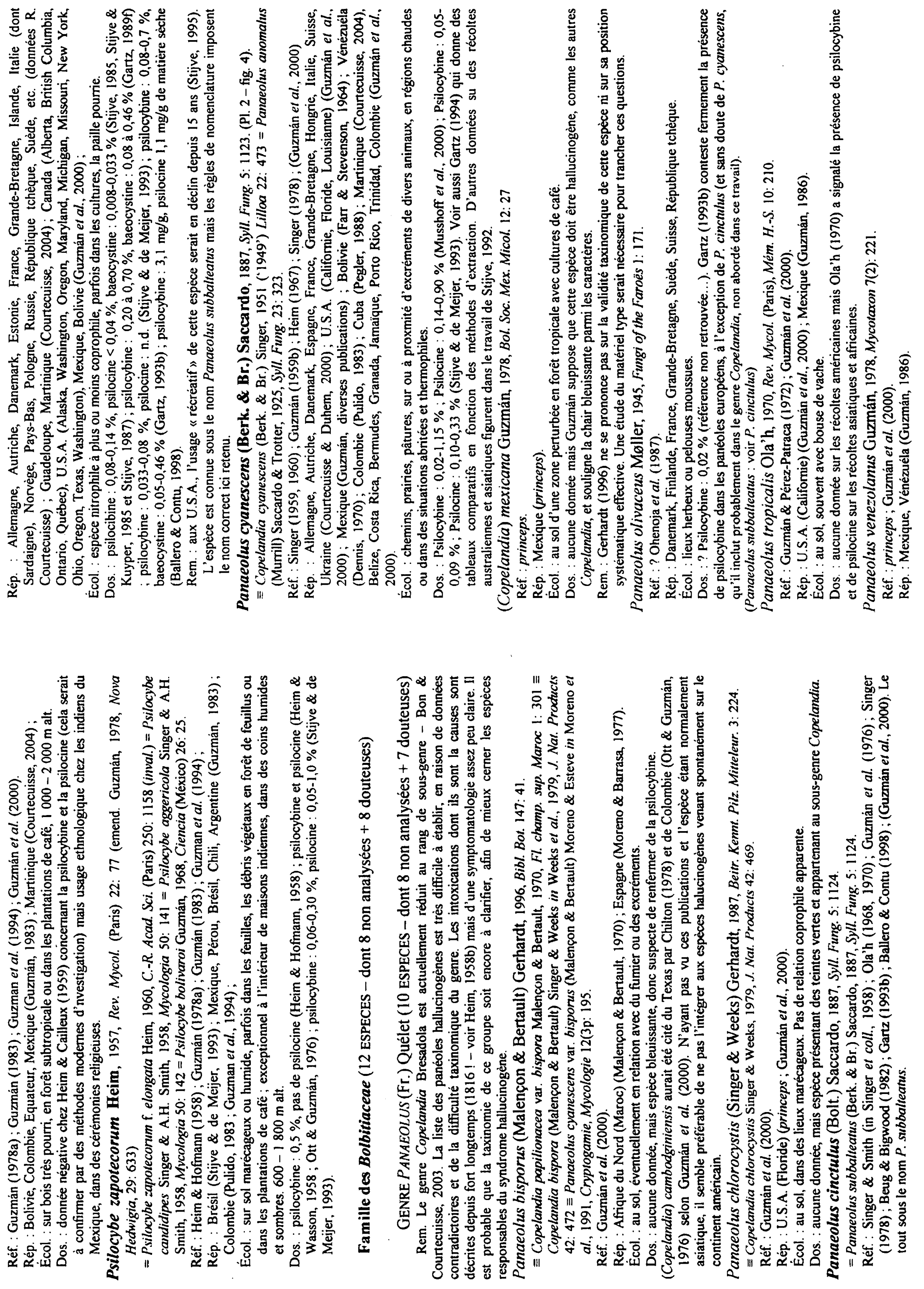

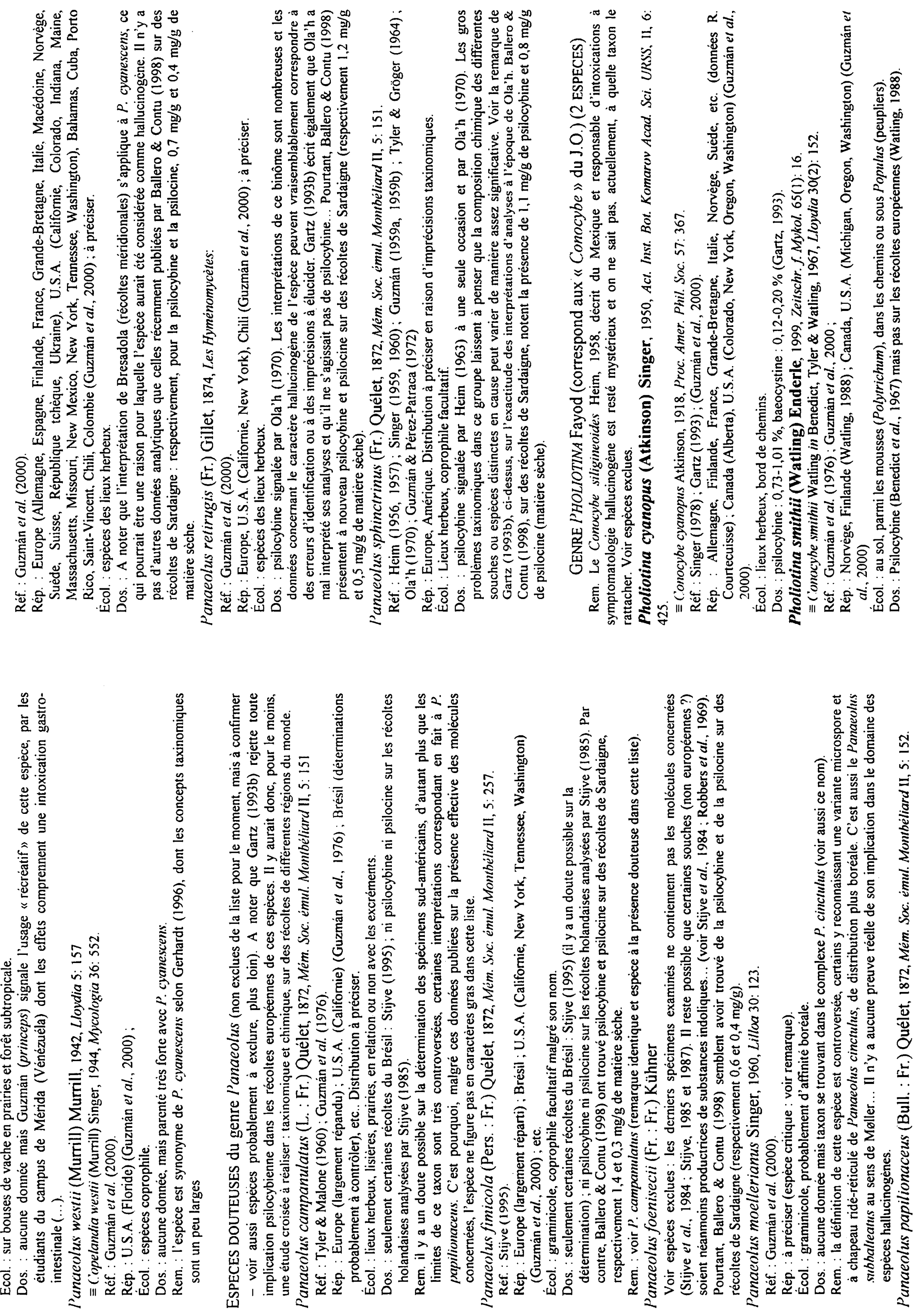

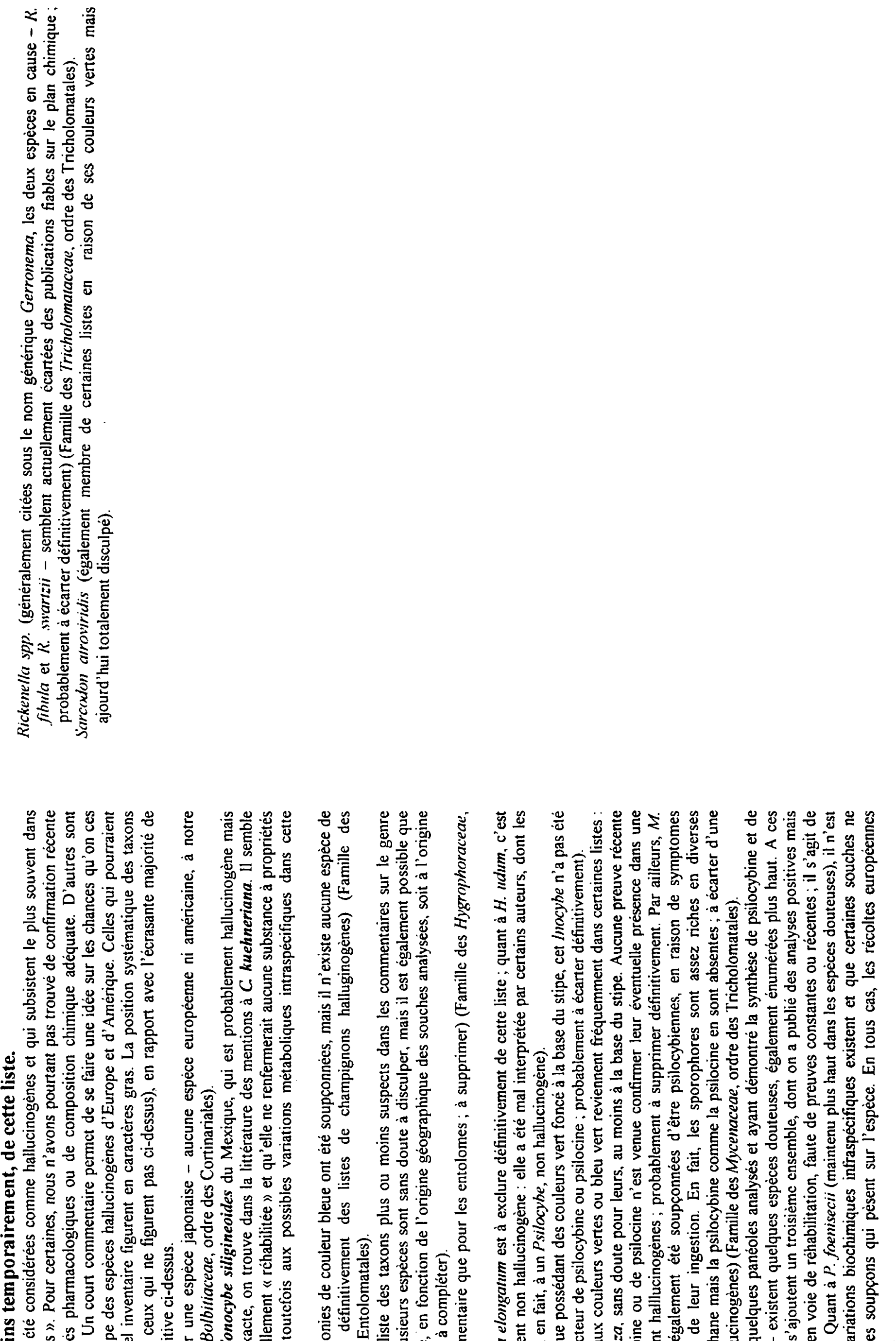

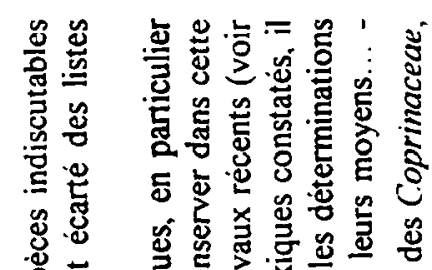

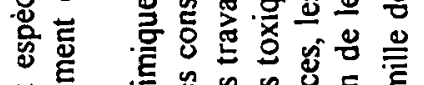

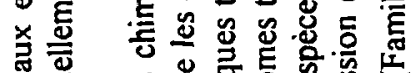
o s क

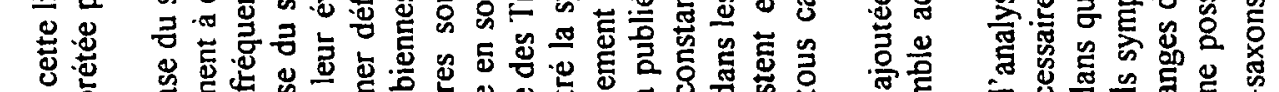

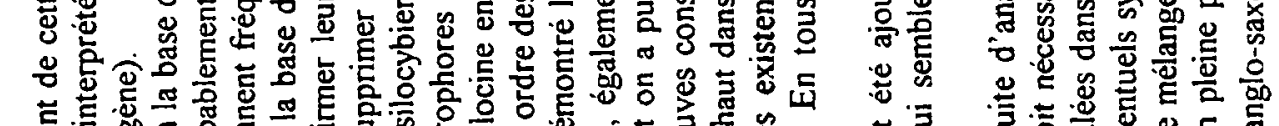

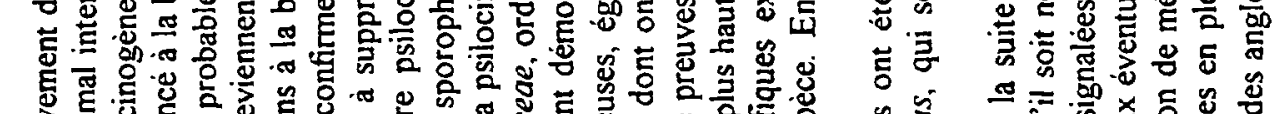
5

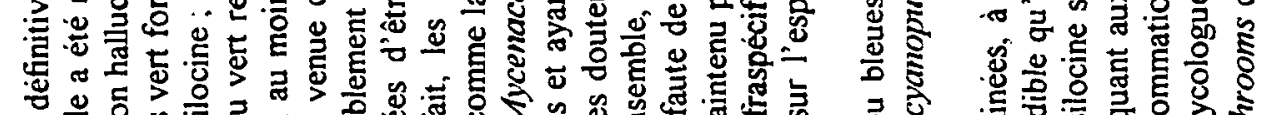

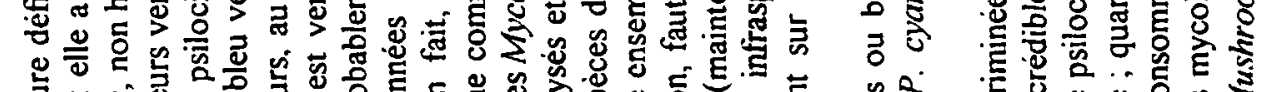

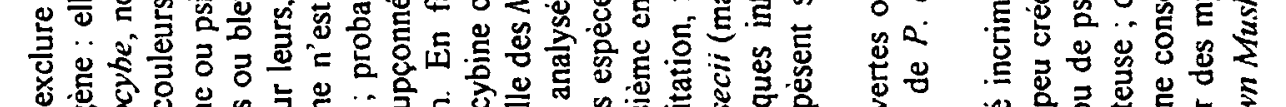

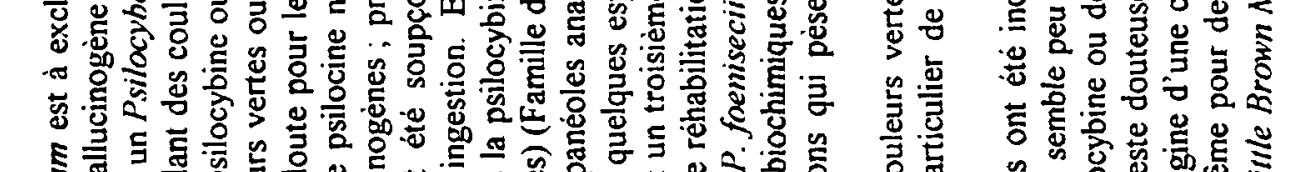

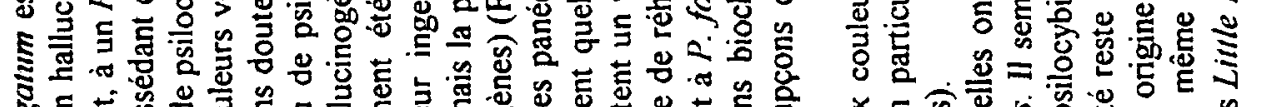

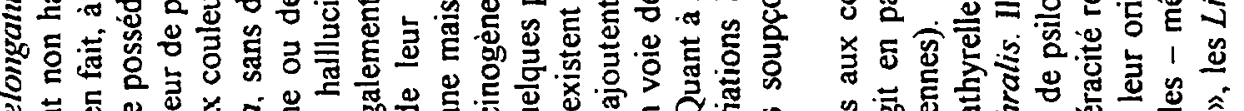

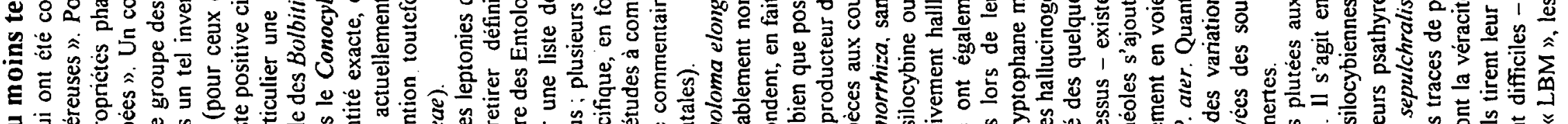

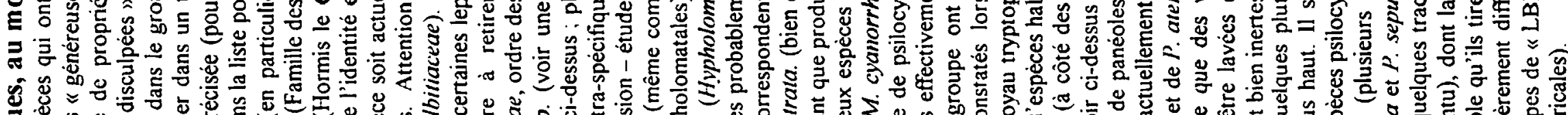

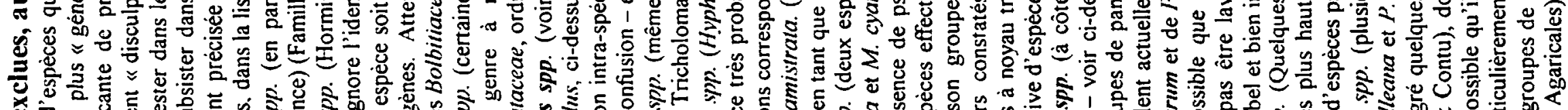

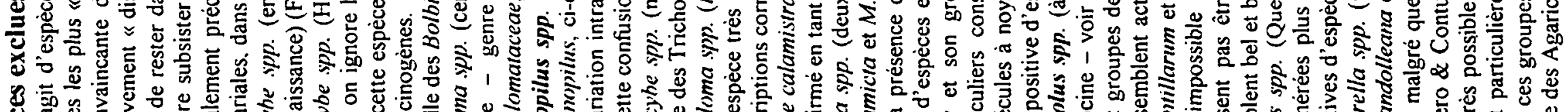

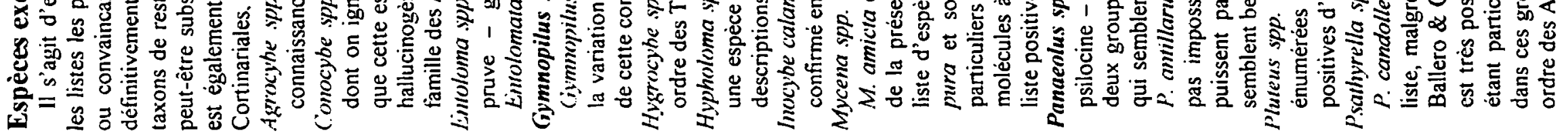




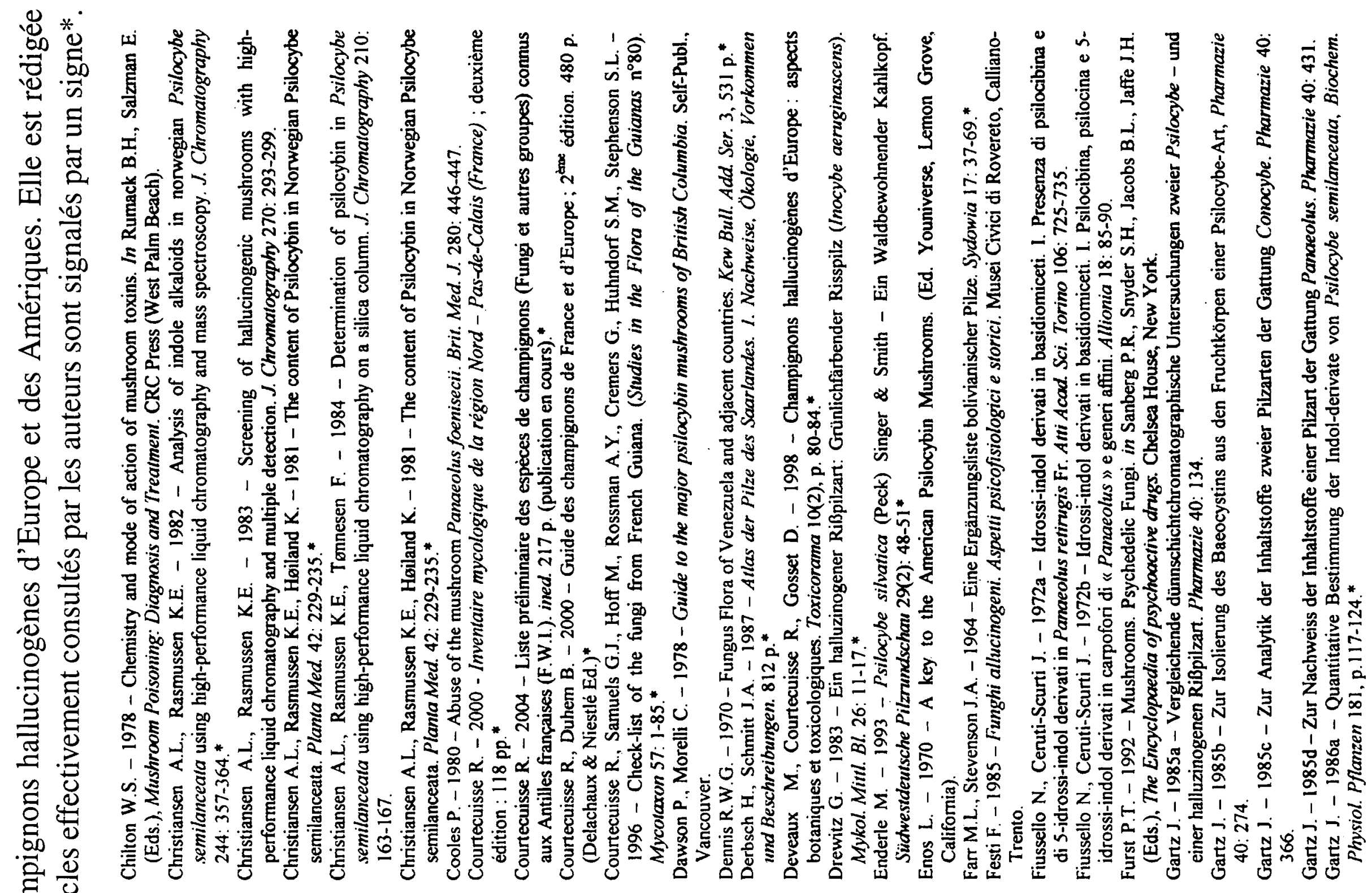

¿

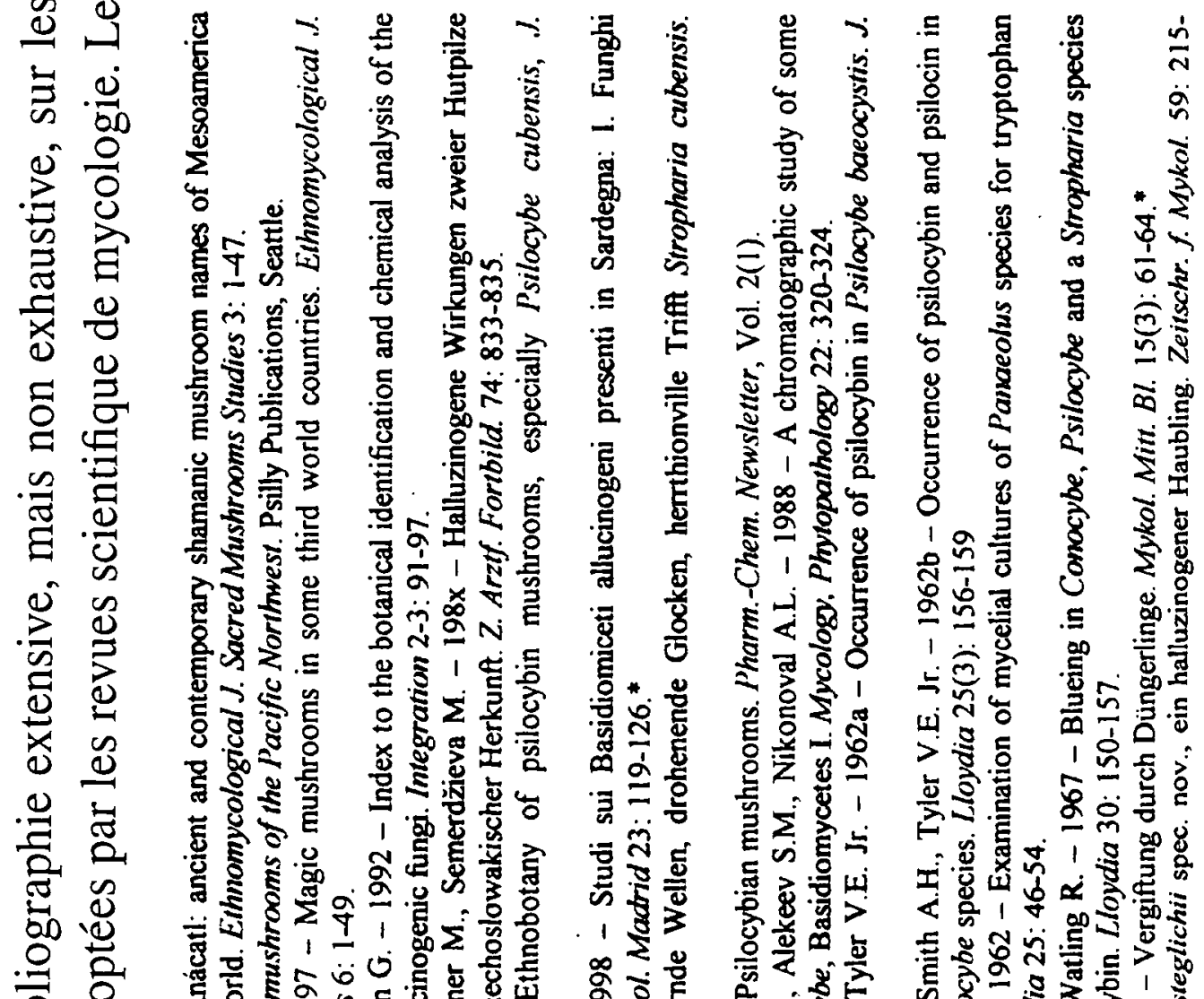

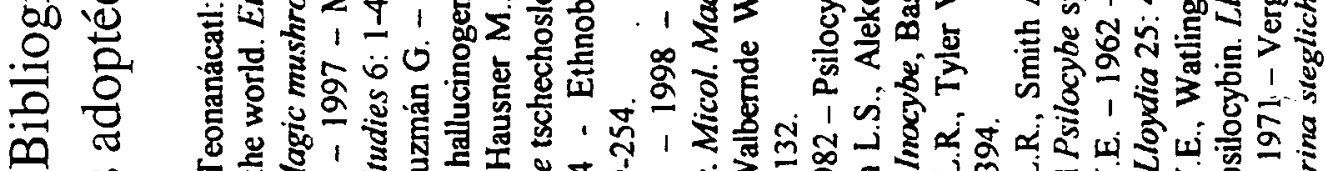

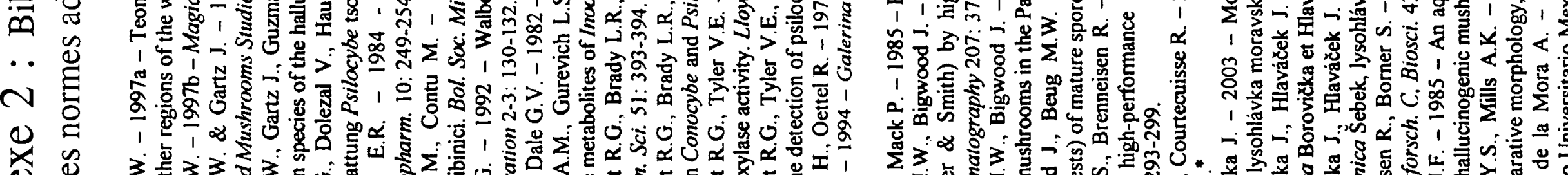

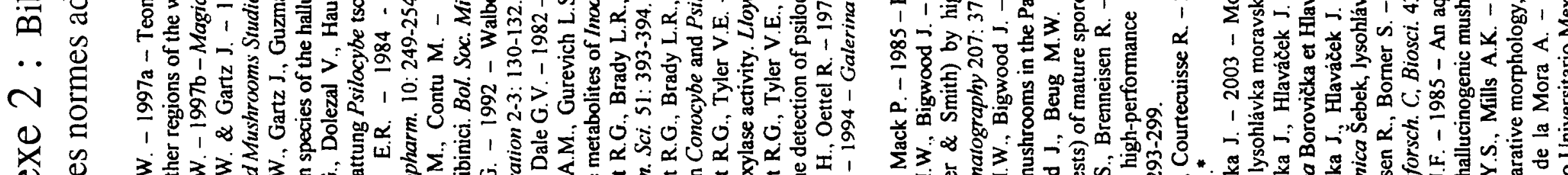

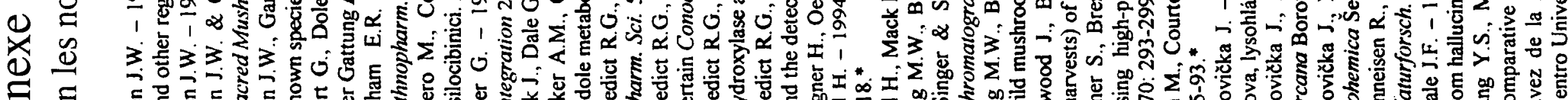

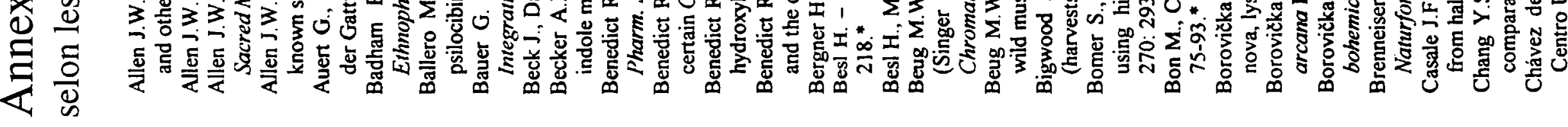




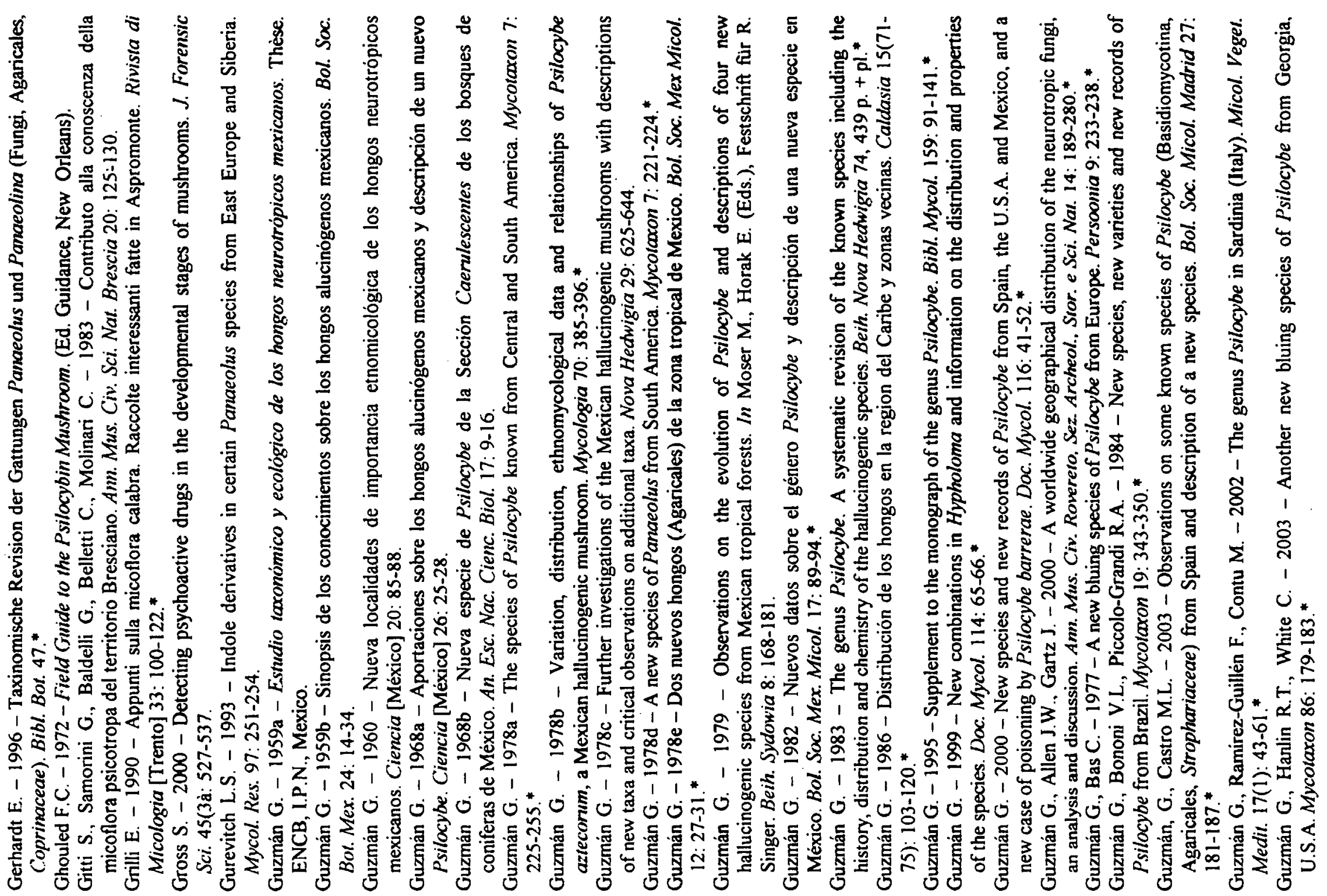

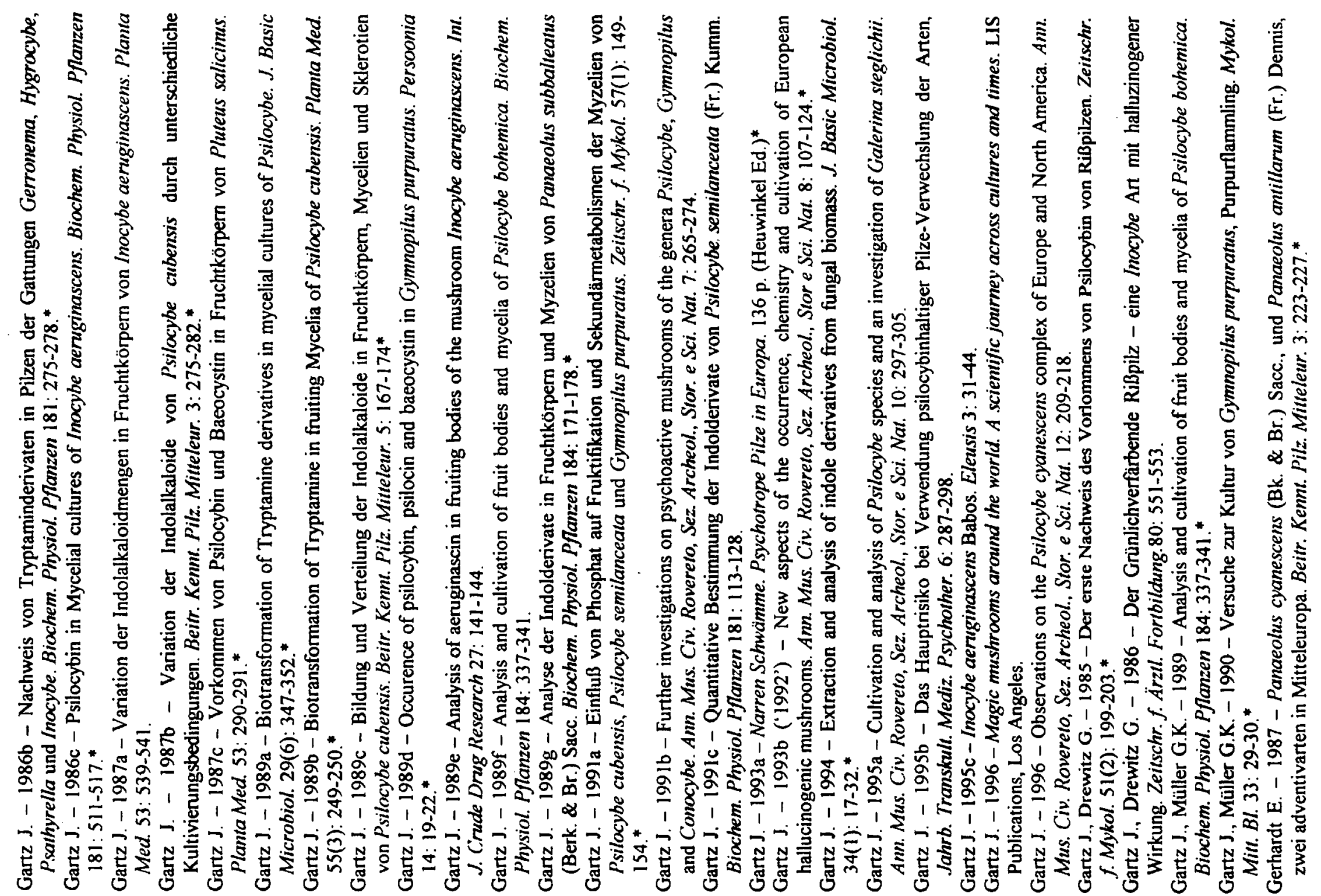




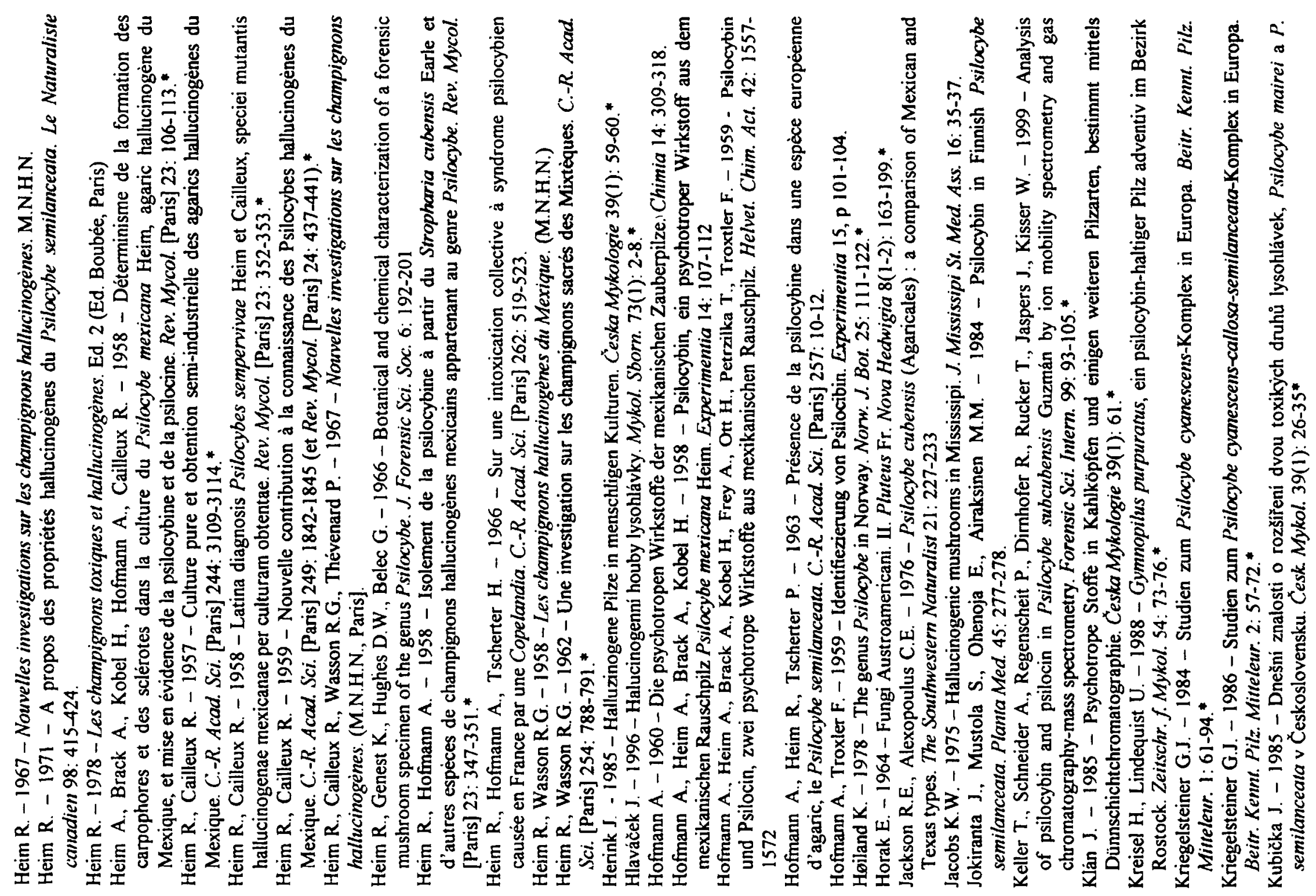

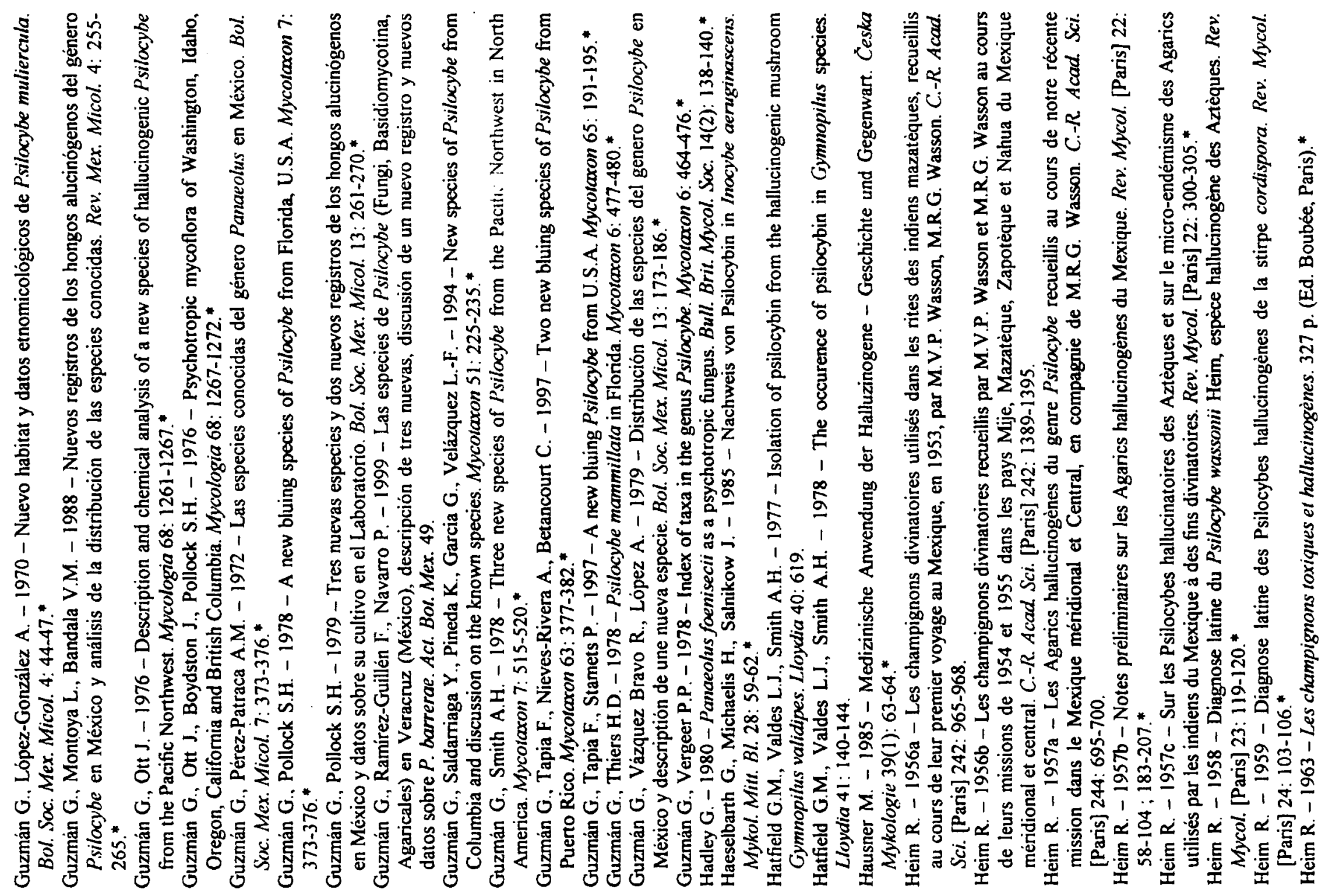




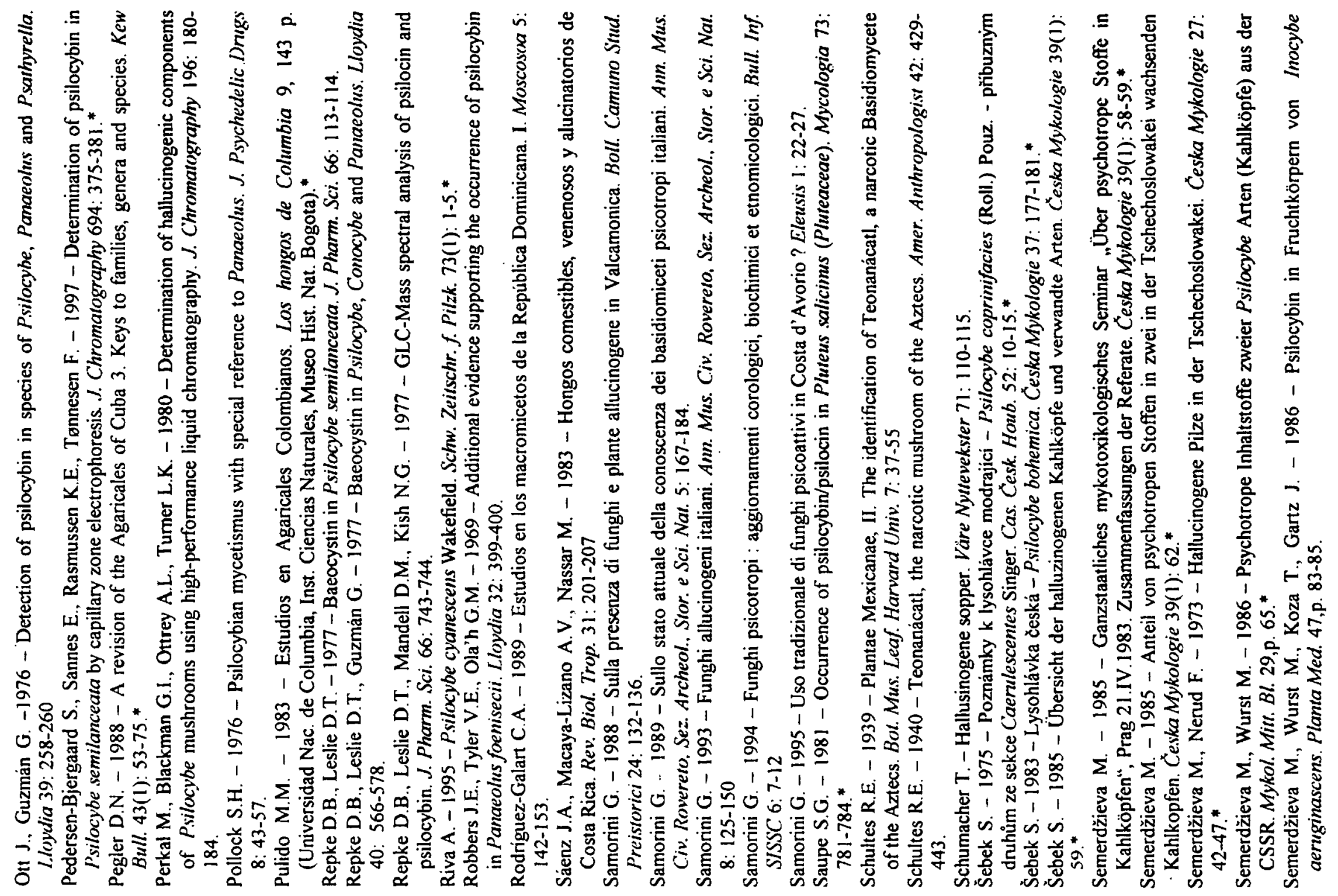

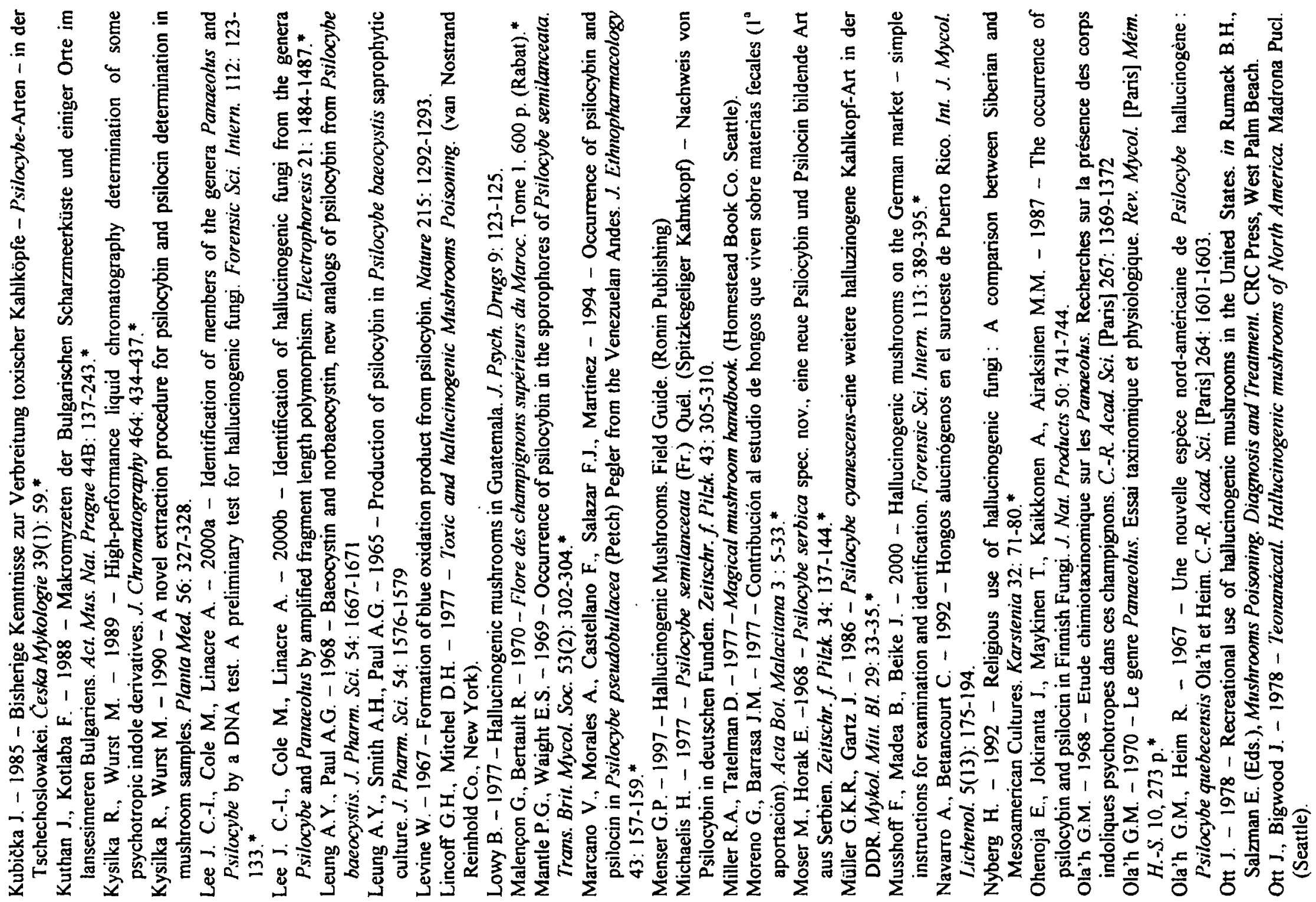




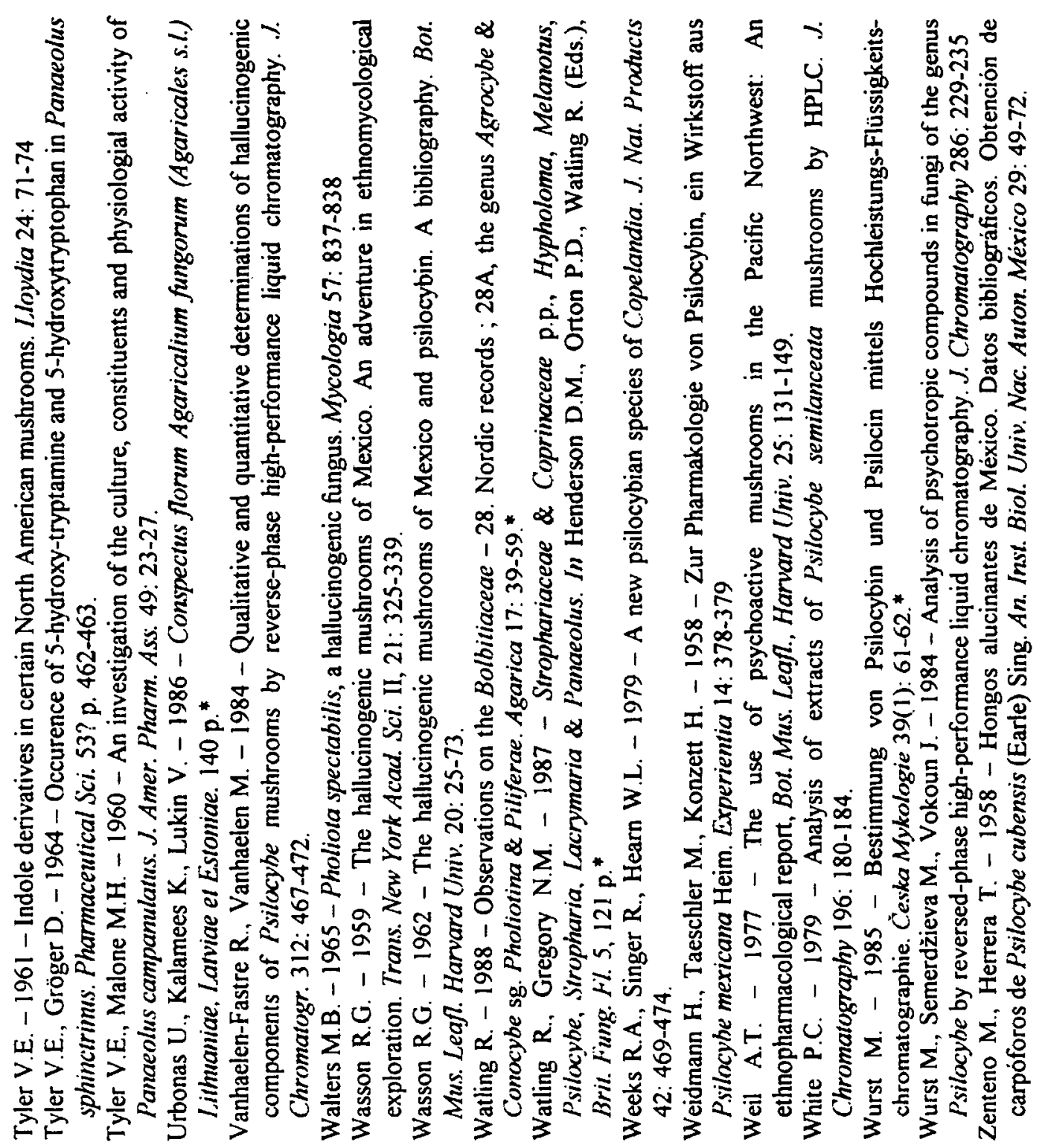

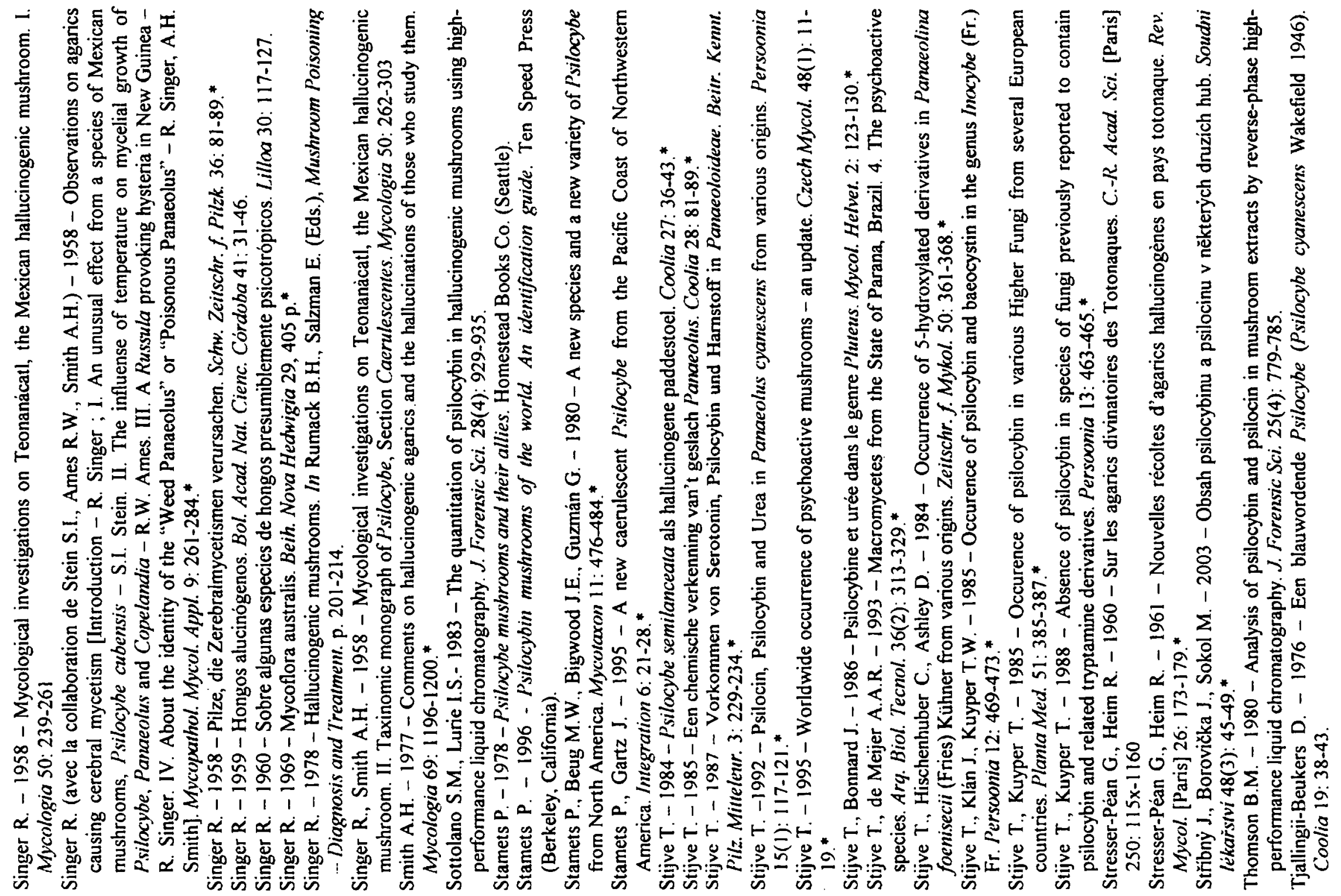

